\title{
Microstrucral, Optical and Electrical Characteristics of Cu-doped CdTe Nanocrystalline Films for Desinging of Absorber Layer in Solar Cell Applications
}

Meshal Alzaid

Jouf University

N. M. A. Hadia

Jouf University

M. El-Hagary

Helwan University

E. R. Shaaban

Al-Azhar University

wael ahmed ( $\square$ wael-saad@science.sohag.edu.eg)

Sohag University Faculty of Science https://orcid.org/0000-0003-4069-8637

\section{Research Article}

Keywords: ITO, Annealing temperature, Microstructural properties, Optical properties, Electrical properties, optoelectronic application

Posted Date: March 18th, 2021

DOI: https://doi.org/10.21203/rs.3.rs-320614/v1

License: (c) (1) This work is licensed under a Creative Commons Attribution 4.0 International License.

Read Full License 


\title{
Microstrucral, optical and electrical characteristics of Cu-doped CdTe nanocrystalline films for desinging of absorber layer in solar cell applications
}

\author{
Meshal Alzaid ${ }^{1, *}$, N. M. A. Hadia ${ }^{1,2}$, M. El-Hagary ${ }^{3}$, E. R. Shaaban ${ }^{4}$, W.S. \\ Mohamed ${ }^{1,2, *}$ \\ ${ }^{1}$ Physics Department, College of Science, Jouf University, P.O. Box: 2014, Sakaka, Saudi \\ Arabia. \\ ${ }^{2}$ Physics Department, Faculty of Science, Sohag University, 82524 Sohag, Egypt \\ ${ }^{3}$ Physics Department, Faculty of Science, Helwan University, 11792 Helwan, Cairo, Egypt. \\ ${ }^{4}$ Physics department, Faculty of Science, Al-Azhar University, Assuit, Egypt
}

*Corresponding author email: wael-saad@science.sohag.edu.eg (W. S.Mohamed), mmalzaid@ju.edu.sa (M. Alzaid)

\begin{abstract}
This paper reports the microstrcure, optical and electrical characteristics of undoped and $\mathrm{Cu}$ doped $\mathrm{CdTe}$ nanostructured thin films prepared on glass substrates by electron beam evaporation technique. The Crystallographic study of X-ray diffraction shows that $\mathrm{CdTe}$ and $\mathrm{Cu}$ doped CdTe films crystallize in the form of a cubic zinc blende structure. Microstructure analysis reveals that as the $\mathrm{Cu}$ doping level increases, the average crystallite size increases, while the microstrian decreases due to the improvement of the crystallinty, thereby reducing defects. XRD and AFM investigations confirmed the nanostructure characteristic of undoped and $\mathrm{Cu}$ doped films. It was found that the optical band gap energy increases from $1.485 \mathrm{eV}$ to 1.683 $\mathrm{eV}$ as the $\mathrm{Cu}$ concentration increases from $0 \mathrm{wt}$. \% to $10 \mathrm{wt}$. \%, which may be related to the Burstein-Moss effect. The refractive index is calculated from the Swanepoel envelope method and found to decrease with the increase of the $\mathrm{Cu}$ doping due to the decrease in the prolizability. Similarly, the extinction coefficient decreases with the increase of $\mathrm{Cu}$ in $\mathrm{CdTe}$ matrix. The dc electrical conductivity is found to increase with increasing $\mathrm{Cu}$ doping, which is attributed to the increase in the grain size, thereby reducing the scattering of the grain boundary. Furthermore, two conduction mechanisms of the carrier transport in nanostrcutured undoped and $\mathrm{Cu}$ doped $\mathrm{CdTe}$ films were observed. The low temperature dependence of the conductivity of undoped and $\mathrm{Cu}$ doped $\mathrm{CdTe}$ nanostructured films is explained based on Mott's variable range hopping conduction mechanism model (VRH). Interestingly, the calculated values of hopping distance $R$, the hopping energy $W$ and the the density of states at the Fermi level $N\left(E_{F}\right)$ are consistent with the Mott's VRH. Finally, Hall effect measurements show that all the films have p- type conduction behavior. Besides, the results show that as $\mathrm{Cu}$ doping level increases, the carrier concentration and the Hall mobility increase due to the decrease in grain boundary scattering with the increase in grain size. Accordingly, it can be concluded that by increasing the $\mathrm{Cu}$ doping level in the CdTe film, the conductivity is increased, thereby improving the performance of the CdTe absorber layer in the solar cell structure.
\end{abstract}

Keywords:

ITO; Annealing temperature; Microstructural properties; Optical properties, Electrical properties; optoelectronic application 


\section{Introduction}

In recent years, the binary semiconductor compounds $\mathrm{A}^{\mathrm{II}} \mathrm{B}^{\mathrm{VI}}$ are provided a great deal of interest due to their potential application in solar cells and photoconductive devices [1]. Cadmium telluride $(\mathrm{CdTe})$ is a member of the $\mathrm{A}^{\mathrm{II}} \mathrm{B}^{\mathrm{VI}}$ semiconductor compound family, which is considered to be one of the most outstanding absorber layers for solar cells because of its unique characteristics such as, direct band gap $(1.5 \mathrm{eV})$ at room temperature located in the central spectrum of the solar spectrum, highly absorption coefficient in the visible region of the solar spectrum $\left(\alpha \approx 10^{5} \mathrm{~cm}^{-1}\right)$ [2], good transport performance, high average atomic number (50), high resistivity, and exhibits n-type and p-type conductivity, which allows the production of solar cells with heterojunction and homojunction structure [3]. CdTe has a sharp absorption edge, which allows $90 \%$ of incident photons to be absorbed in a $2 \mu \mathrm{m}$ opaque CdTe layer, whereas the absorption of similar radiation intensity needs thick layer of $20 \mu \mathrm{m}$ in the case of Si [4] All these characteristics make CdTe an ideal candidate materials for various applications, e.g. photovoltaic conversion, solar cell structure, field effect transistors, and X-ray and gamma-ray detectors [role 5, 6]. Several deposition techniques have been used to fabricate CdTe thin films, such as rf sputtering. [7], chemical bath deposition, [8], pulsed laser deposition [9], close-range sublimation [10], electro deposition [11], thermal evaporation [12] and Electron beam evaporation [13]. Nevertheless, the difficult duty is to obtain a stoichiometic CdTe films to better design the absorber layer in the solar cell structure, since defects and/or impurities generated during the deposition process will affect the optoelectronic properties of prepared thin films, thereby changing the efficiency of the solar cells [14, 15-17]. Also, it is reported that the electrical and optical properties of CdTe thin films are tuned by doping with appropriate dopant $(\mathrm{Bi}, \mathrm{Co}, \mathrm{Ag}, \mathrm{Cu}, \mathrm{In}$ and 
Mo) into CdTe semiconductor lattice, which enhances the efficiency of solar cells

[18-23]. In this context, $\mathrm{Cu}$ was reported to be an amphoteric dopant type, that can involve in the CdTe lattice as an interstitial ion $\left(\mathrm{Cu}_{i}^{+}\right)$, producing a shallow donor level, or substituted by $\mathrm{Cd}$ atoms to form a deeper acceptor level $\left(\mathrm{Cu}^{-}{ }^{-}\right)$, or complexes contains $\mathrm{Cu}^{+}$and $\mathrm{Cd}$ vacancies $\left(\mathrm{Cu}_{\mathrm{i}}{ }^{+}+\mathrm{V}_{\mathrm{Cd}^{-2}}\right)$ and $\left(\mathrm{Cu}^{+}-\mathrm{Cu} \mathrm{Cd}\right)$, forming a shallow acceptors [24]. One of the main advantages of $\mathrm{Cu}$ doping into $\mathrm{CdTe}$ is the increase in carrier concentration, which can improve the ohmic contact.

In this paper, electron beam evaporation technique is used to deposite high quality undoped and $\mathrm{Cu}$ doped $\mathrm{CdTe}$ nanocrystalline thin films with different $\mathrm{Cu}$ concentrations on a glass substrates. The detailed analysis of the microstructur, morphology, optical and electrical properties of $\mathrm{CdTe}$ and $\mathrm{Cu}$ doped $\mathrm{CdTe}$ nanocrystalline films is studied, which is very important for the design of the absorber layer in the solar cell structure.

\section{Materials and Methods}

CdTe and $\mathrm{Cu}$ doped $\mathrm{CdTe}$ ingots with different $\mathrm{Cu}$ concentrations $(0,2,4,6$, 8, and 10 wt. \%) have been synthesized using mechanical mailing method. Analytical grades with stoichiometric $\mathrm{CdTe}$ and $\mathrm{Cu}_{2} \mathrm{Te}$ powders (with a chemical purity of (99.999\%, Aldrich) were mixed together and milled in a mechanical ball mill machine at $200 \mathrm{rpm}$ for 6 hours. The mixture is made into disk-shaped to avoid splashing the mixture powders during the evaporation process. The prepared pure and $\mathrm{Cu}$ doped CdTe ingots were used as a source for thin film deposition. The CdTe and $\mathrm{Cu}$ doped CdTe thin films with various $\mathrm{Cu}$ concentrations were deposited by electron beam evaporation technique (Edward Auto 306) at room temperature. Amorphous glass with a size of $(25 \mathrm{~mm} \times 25 \mathrm{~mm})$ is used as the substrate. To clean the substrate carefully, the substrate was immersed in acetone for 15 minutes, then washed with purified water for 15 minutes, and subsequently with alcohol for 10 minutes. At last, 
the substrate was ultrasonically cleaned in deionised water for 15 minutes, and then was dried in air at a temperature of $100^{\circ} \mathrm{C}$. The substrates and ingots have been placed in the chamber, which was then evacuated at pressure of $5 \times 10^{-6} \mathrm{~Pa}$. The pellet ingot was preheated for 5 minutes before evaporation to remove any pollutants and degas the pellets. The distance from the substrate to the source is kept at about $20 \mathrm{~cm}$. The thickness of the film was adjusted at $300 \mathrm{~nm}$ at a deposition rate of $2 \mathrm{~nm} / \mathrm{sec}$, which was controlled by a thickness monitor device (model; FTM6). More details of the deposition methodology are explained elsewhere [25].

X-ray diffractometer (XRD, $\mathrm{Cu}-\mathrm{K} \alpha=1.54056 \AA$, Philips diffraction 1710) was used for crystallographic investigation. The ratio of the elemental composition of the film was checked by using energy dispersive X-ray spectroscopy (EDXS). The surface morphology of the film was performed using an atomic force microscope (AFM, model MLCT-MT-A). The transmission and reflection spectra were measured with a dual beam spectrophotometer (UV-VIS-NIR, Shimadzu model V-670). The electrical performance was studied by using the Hall measurement technique in van der Pauw configuration with a 0.6 T magnetic field (model Ecopia-HMS-3000).

\section{Results and discussion}

\subsection{Elemental composition analysis}

The elemental composition analysis of $\mathrm{Cu}$-doped films with different $\mathrm{Cu}$ doping levels has been performed by EDXS measurement. Fig. 1 represents the EDXS spectra CdTe:Cu 2 wt. \% and CdTe:Cu 10 wt. \%. The spectra of the $\mathrm{Cu}$ doped films confirmed the appearance of three peaks corresponding to $\mathrm{Cd}$, $\mathrm{Te}$, and $\mathrm{Cu}$. The spectra further show that the peak intensity of $\mathrm{Cu}$ increases with the increase of $\mathrm{Cu}$ doping, which indicates the stoichiometry of the film and $\mathrm{Cu}$ ions have been successfully incorporated into the CdTe matrix. 

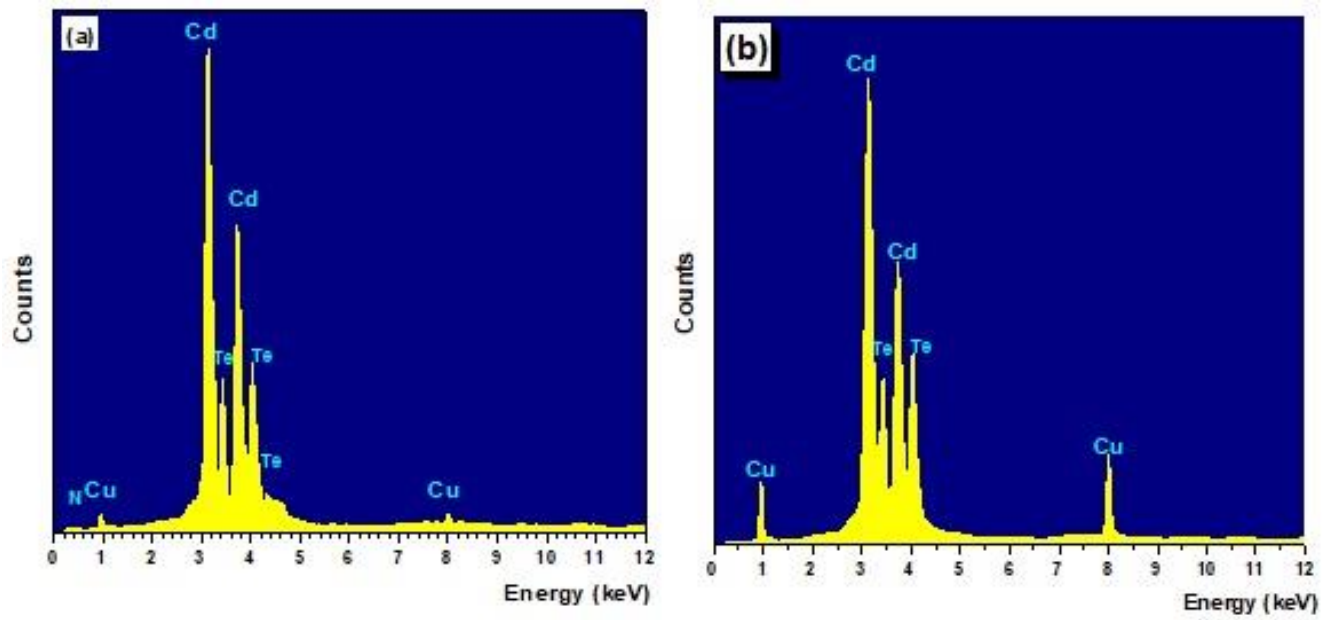

Fig. 1 EDXS of the Cu doped CdTe films.

\subsection{Structural and microstructure characterizations}

Fig. 2(a) shows the XRD spectra of undoped and $\mathrm{Cu}$ doped CdTe (CdTe:Cu) thin films deposited by electron beam evaporation method at room temperature on glass substrate with different $\mathrm{Cu}$ concentrations of 2, 4,6,8,10 wt. \% . The results reveal that all films have a polycrystalline like structure with three reflection lines belonging to (111), (220) and (311) diffraction planes of cubic zinc blende structure suggested the existence of the cubic phase of CdTe structure; see (JCPDS No. 01075-2086). In addition, the XRD pattern reveals a preferred oriented grain growth toward (111) plane due to the challenge between energy of surface and strain energy [26]. It is worth noting that, the XRD spectra did not show any foreign peak related to copper phases such as copper oxide and or copper cluster, indicating a successful inclusion of $\mathrm{Cu}^{2+}$ ions into the CdTe lattice without change of cubic structure of CdTe. It was found from Fig. 2(b) that the peak position of (111) plane is shifted towards higher diffraction angles due to the strain in the film by the incorporation of $\mathrm{Cu}$ ions in the $\mathrm{CdTe}$ structure of semiconductor matrix with remarkable shrinks in the cell volume. Fig. 3 shows the reduction of the lattice parameter (a) with increasing of 

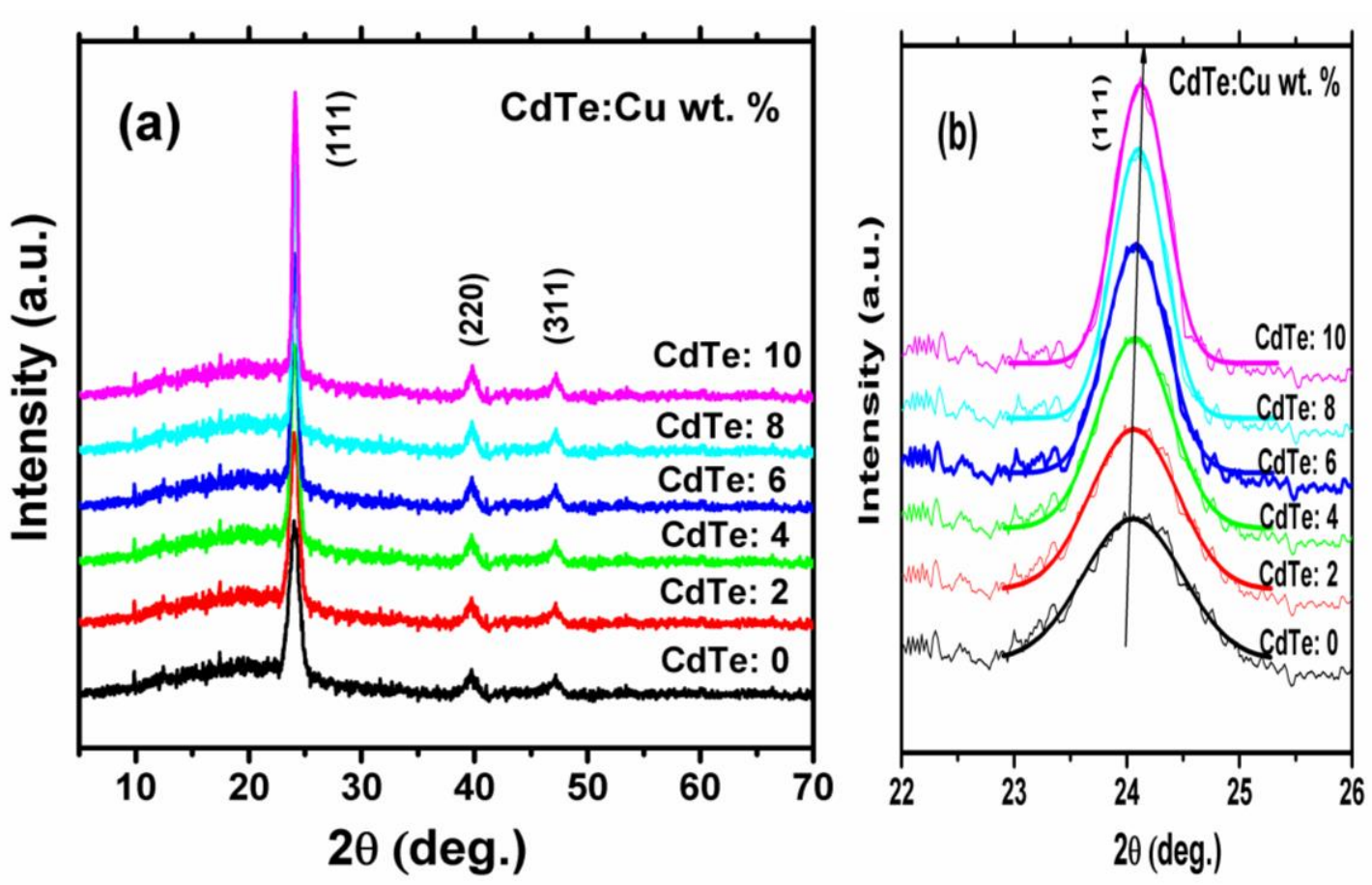

Fig. 2 (a) XRD diagrams of undoped and $\mathrm{Cu}$ doped thin films at $\mathrm{Cu}$ concentrations, (b) The magnification of diffraction peak at (111) plane.

$\mathrm{Cu}$ incorporation into $\mathrm{CdTe}$ host lattice which are calculated from interspacing planner distance (d) and lattice indices (hkl) of the most predominantly preferred oriented peak by using the standard equation of cubic structure: $a=d \sqrt{a^{2}+b^{2}+c^{2}}$. The observed reduction of the lattice parameter is attributed the incorporation of $\mathrm{Cu}^{2+}$ ions of smaller ionic radius $(0.72 \AA)$ by $\mathrm{Cd}^{2+}$ ions of larger ionic radius $(0.97 \AA)$. The calculated value of the lattice parameter of $\mathrm{Cu}$ doped film with different $\mathrm{Cu}$ doping levels is tabulated in Table 1. As can be seen the obtained lattice parameter (a) value of undoped CdTe is consistent with the standard value of CdTe cubic structure (6.41 $\mathrm{A}^{\circ}$, JCPDS No. 01-075-2086). Furthermore, the intensity of the preferred oriented peak (111) is improved and its full width at half maximum of diffraction peak (FWHM) decreases with the increase of the $\mathrm{Cu}$ doping, which are attributed to the improvement of the crystal growth of the film due to the occupation of $\mathrm{Cd}$ site by $\mathrm{Cu}$ ions. This behaviour was given in literature for $\mathrm{CdTe}$ doped $\mathrm{Mo}$ [24] and $\mathrm{CdTe}$ doped $\mathrm{Cu}$ thin films [27]. In addition, the nanostructure 


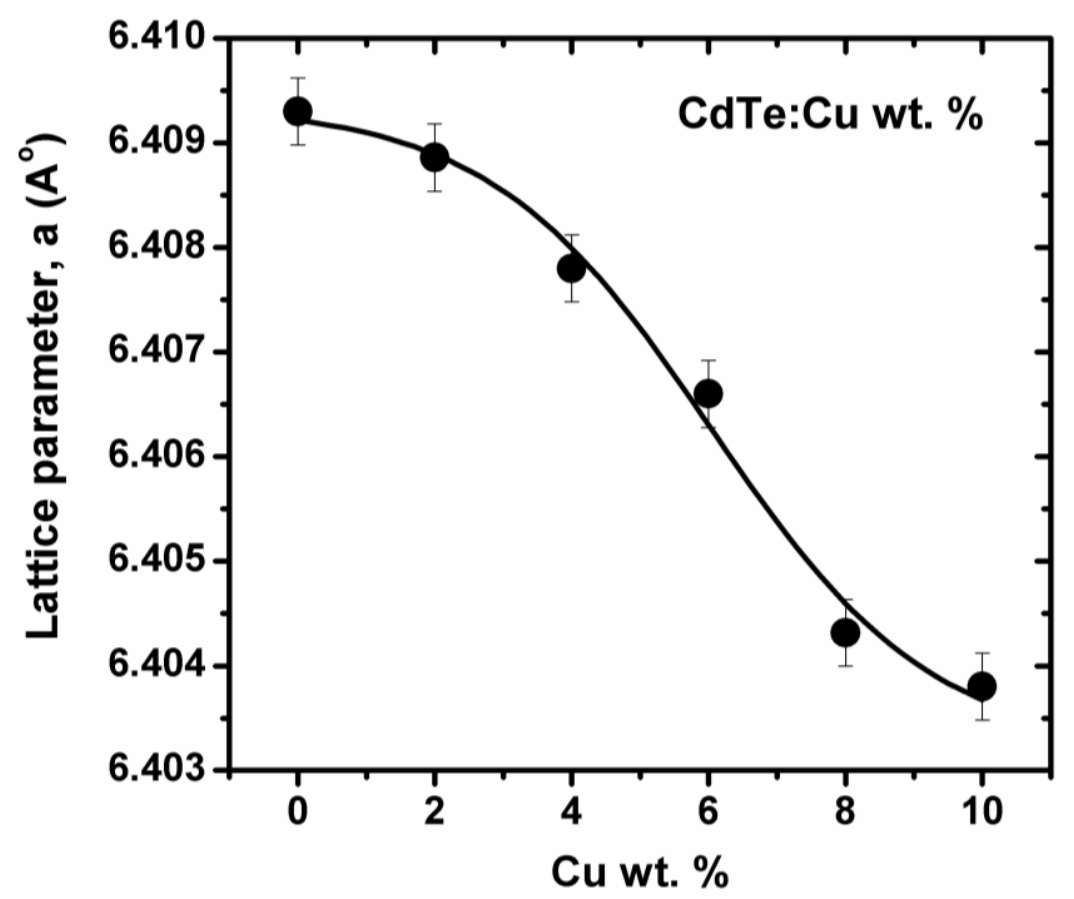

Fig. 3 The lattice parameter versus $\mathrm{Cu}$ doping concentration in $\mathrm{CdTe}$ matrix.

nature of the films is examined by using Debye-Scherrer's equations from the calculations of the mean crystallite sizes, $D=\frac{k^{\prime} \lambda}{\beta \cos \theta}$ and lattice microstrain, $\varepsilon=\frac{\beta}{4 \tan \theta}$ where, $\theta, \beta, k^{\prime}$ and $\lambda$ are the Bragg angle of most preferred oriented peak, radian FWHM, shape factor $(\approx 0.9)$ and the wavelength of the $\mathrm{CuK}_{\alpha}$ radiation, respectively. The value of the average crystallite size of the $\mathrm{Cu}$ doped CdTe film is found to vary from $16.07 \mathrm{~nm}$ for CdTe to $28.87 \mathrm{~nm}$ for CdTe:10 wt. \%, confirming the nanostructure characteristic of the film. Fig. 4 displays the dependence of the microstructure parameters with $\mathrm{Cu}$ doping, see also Table 1. It can be seen that as the $\mathrm{Cu}$ doping increases, the average crystallite size increases while the microstrian decreases which refers to improvement of the crystallinty and the reduction of the defects due to the completely integration of $\mathrm{Cu}^{2+}$ ions into the $\mathrm{CdTe}$ lattice. Such increase in the average crystallite size and decrease in microstain is reported for films that have smaller ionic radius dopants [28]. 


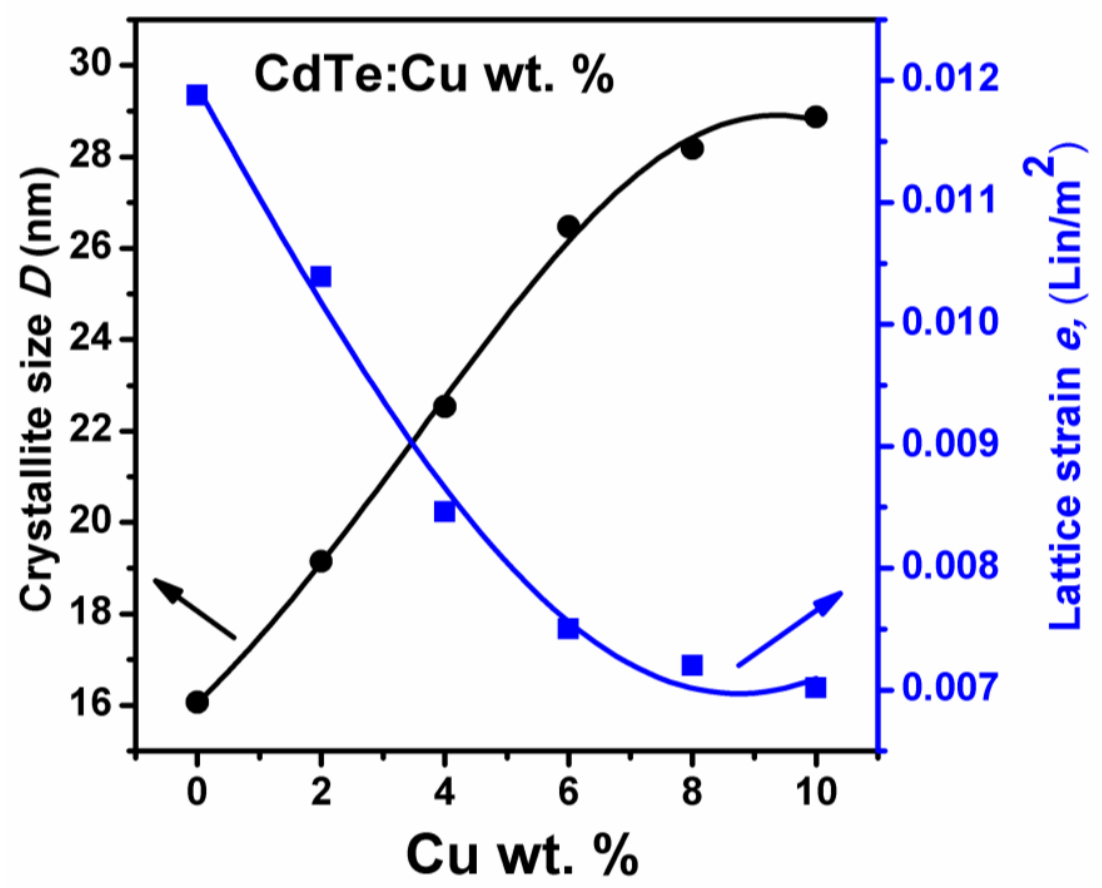

Fig 4 The variation of the microstructural parameters with different $\mathrm{Cu}$ concentrations of undoped and $\mathrm{Cu}$ doped $\mathrm{CdTe}$ films.

Table 1 Structural, microstructural of undoped and $\mathrm{Cu}$ doped CdTe thin films

\begin{tabular}{|c|c|c|c|c|c|c|c|}
\hline CdTe:Cu & $(\AA)$ & $(\AA)^{3}$ & $\begin{array}{c}\text { Average Crystallite } \\
\text { size obtained from } \\
\text { XRD } \\
(n m)\end{array}$ & $\begin{array}{c}e \times 10^{-3} \\
\left(\mathrm{Lin} / \mathrm{m}^{2}\right)\end{array}$ & $\begin{array}{l}\text { Average } \\
\text { grain size } \\
\text { obtained } \\
\text { from AFM } \\
(\mathrm{nm})\end{array}$ & $\begin{array}{c}\text { Surface } \\
\text { roughness }\end{array}$ & $\begin{array}{c}\text { RMS } \\
\text { Surface } \\
\text { roughness } \\
\text { (nm) }\end{array}$ \\
\hline 0 & 6.4093 & 263.29 & 16.07 & 1.19 & 28.61 & 2.446 & 2.283 \\
\hline 2 & 6.4089 & 263.23 & 19.15 & 1.04 & 34.34 & 2.102 & 2.112 \\
\hline 4 & 6.4078 & 263.10 & 22.54 & 0.85 & 41.12 & 1.283 & 1.113 \\
\hline 6 & 6.4066 & 262.95 & 26.47 & 0.75 & 43.56 & 1.134 & 1.072 \\
\hline 8 & 6.4043 & 262.67 & 28.18 & 0.72 & 49.56 & 0.812 & 0.623 \\
\hline 10 & 6.4038 & 262.61 & 28.87 & 0.70 & 56.23 & 0.622 & 0.420 \\
\hline
\end{tabular}

\subsection{Surface morphology analysis}

The microscopic description of the surface morphology of the undoped and $\mathrm{Cu}$ doped CdTe films has been performed using AFM investigation. Fig. 5 shows the three dimensional (3D) AFM images of CdTe, CdTe:4 and CdTe:10 films. The images show that the surface of the films has a highly densely spherical elongated packing grain with uniform arrangement. The observed regular distribution of the elongated spherical grains with similar directions confirms the observed preferred oriented grain 
growth toward (111) plane. The micrographs of the $\mathrm{CdTe}$ and $\mathrm{Cu}$ doped films were analyzed in details in order to identify the microscopic surface morphology parameters, such as the grain size, surface roughness and root mean square (RMS) surface roughness, see Table 1. The data shows that the grain size increases with the increase of the $\mathrm{Cu}$ concentration into $\mathrm{CdTe}$ lattice. However, it was found that the surface roughness and RMS surface roughness are decreased with the increase of the $\mathrm{Cu}$ doping. The reduction in the surface roughness with the increase of $\mathrm{Cu}$ doping into CdTe films [27] and $\mathrm{ZnO}$ films [29] is reported in literature. It has to be mentioning that the grain size obtained from SEM is higher than the crystallite size calculated by XRD. This inconsistency can be ascribed to the fact that the crystallite size is a record of the size coherent scattering domain, whilst the grain size is a set of this coherently scattering domain separated by grain boundary. Besides, crystallite size reveals two distinct ranges when dislocations are located in the composition, while the difference between them is not visible in the SEM micrographs [30]. 


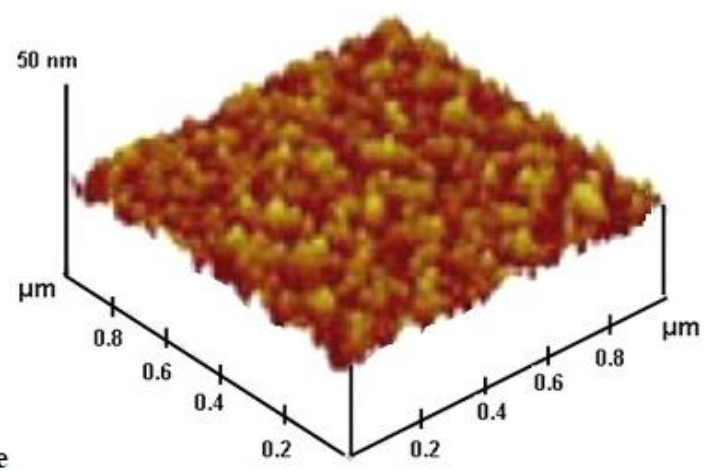

(b) CdTe:4

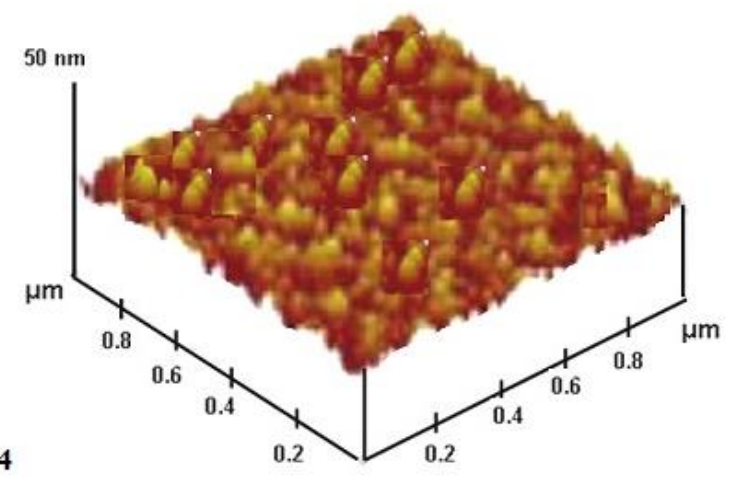

(c) CdTe:10

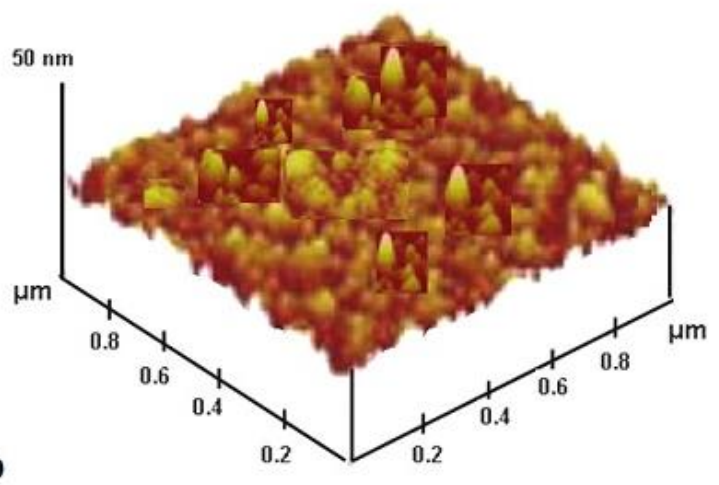

Fig. 5 3D AFM micrographs of $\mathrm{Cu}$ doped CdTe films. 


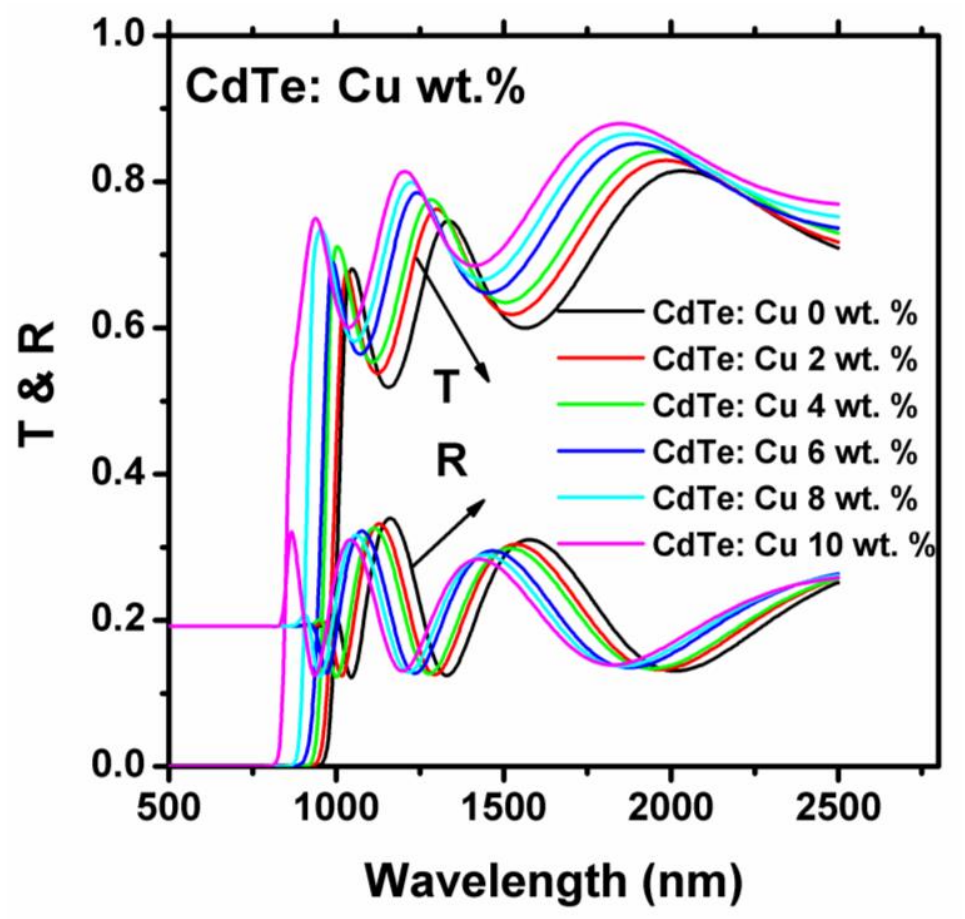

Fig. 6 The spectral variation of the transmittance and refractance of pue and $\mathrm{Cu}$ doped CdTe films with various $\mathrm{Cu}$ contents.

\subsection{Optical properties}

The optical band gap energy of the semiconductor films is calculated from absorption spectra of the films via their transmission and reflection measurements. Fig. 6 shows the spectral dependence of transmittance measurement $T$ of nanocrystalline $\mathrm{Cu}$ doped $\mathrm{CdTe}$ film with various $\mathrm{Cu}$ doping levels in wavelength range $(200-2500 \mathrm{~nm})$. The average transmittance in the near infrared region was found to vary from $78 \%$ to $82 \%$. Thus, the highly transparent $\mathrm{Cu}$ doped $\mathrm{CdTe}$ films can be used in n-type window layer for photovoltaic solar cells applications as reported for highly transmission $\mathrm{CdS}$ film [31,32] and $\mathrm{CdO}[33]$ thin film. It is 


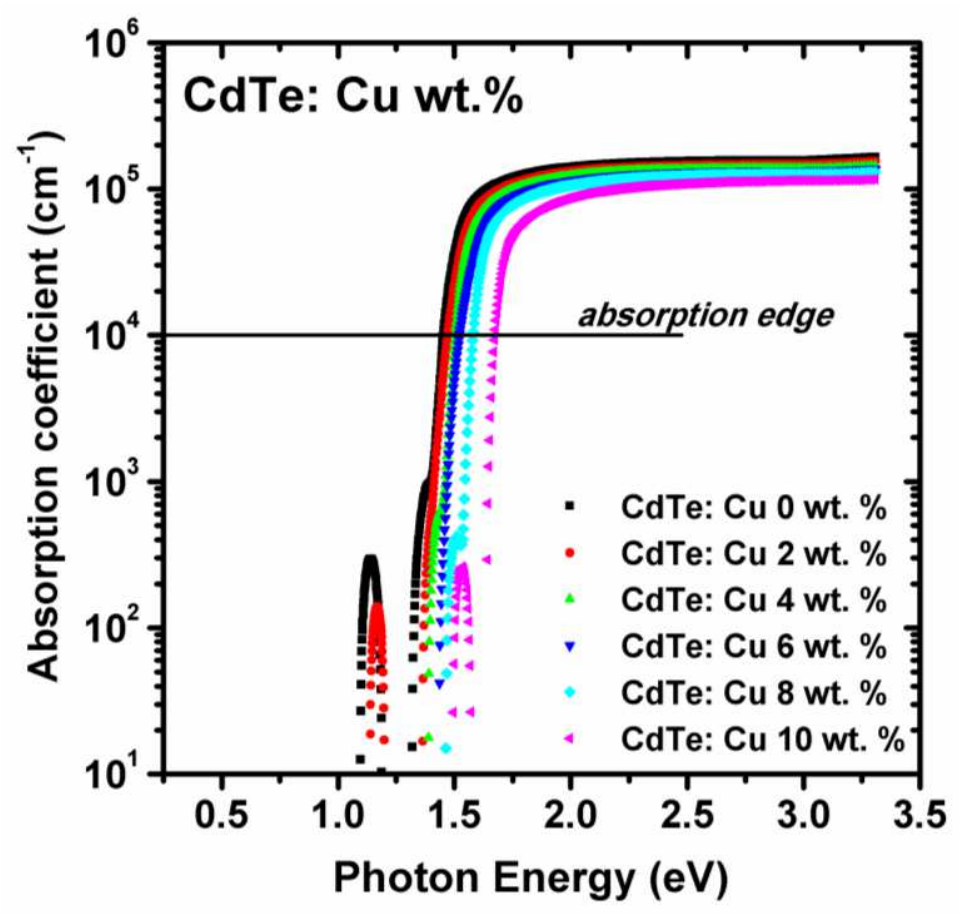

Fig. 7 The absorption coefficient versus photon energy of pure and $\mathrm{Cu}$ doped $\mathrm{CdTe}$ films at different $\mathrm{Cu}$ dopants.

clearly seen that the transmittance reasonably increases with the increment of the $\mathrm{Cu}$ content into the CdTe host lattice which is attributed to the improvement of the crystallinity, see XRD analysis. The thickness uniformity and surface smoothness of the film can be verified by the appearance of interference fringes, which is due to the coherence of multiple of transmitted lights at the interface between the film and substrate. Furthermore, the transmission curve drops sharply at the absorption edge due to the transition of electron from valence band (VBM) to conduction band $(\mathrm{CBM})$. It is found further that as the concentration of $\mathrm{Cu}$ into $\mathrm{CdTe}$ increases, the absorption edge blue shifts, which indicates that the fundamental energy gap increases with the increase of $\mathrm{Cu}$ doping. Fig. 7 depicts the absorption coefficient as a function in photon energy of nanostructured $\mathrm{Cu}$ doped $\mathrm{CdTe}$ film with different $\mathrm{Cu}$ dopants, which are evaluated from the transmission and reflection measurements in the strong absorption region by using the following relation [34]: 


$$
\begin{aligned}
& \alpha(\lambda)=\left(\frac{1}{d}\right) \ln (X \times Y) \\
& X=\left[\left(1-R_{1}\right)\left(1-R_{2}\right)\left(1-R_{3}\right)\right] /\left[2 T\left(1-R_{2} R_{3}\right)\right],
\end{aligned}
$$

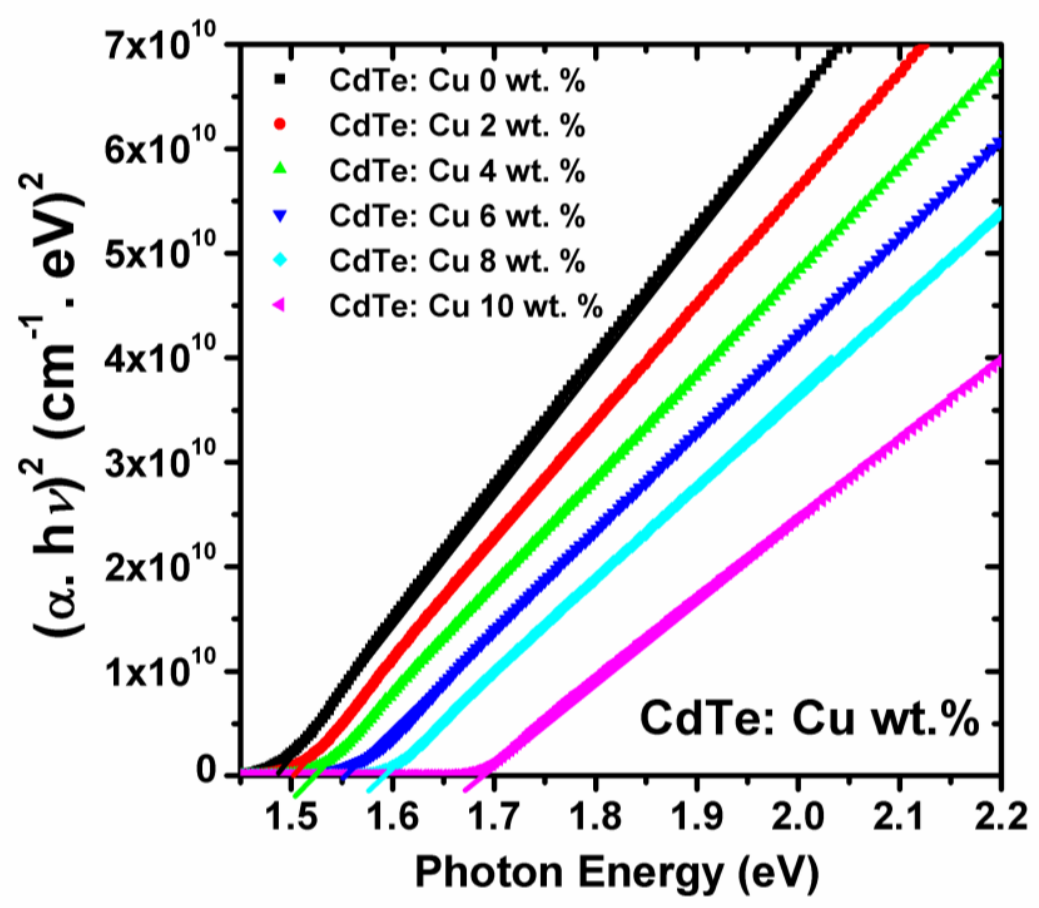

Fig. $8(\alpha h v)^{2}$ versus hv of undoped and $\mathrm{Cu}$ doped $\mathrm{CdTe}$ films at different $\mathrm{Cu}$ contents.

and

$$
\left.Y=1+\left\{1+\left[R_{1}\left(R_{2}+R_{3}-2 R_{2} R_{3}\right)\right] /\left(1-R_{2} R_{3}\right) A^{2}\right]\right\}^{1 / 2}
$$

where $d$ is film thickness, and $R_{1}, R_{2}$, and $R_{3}$ the power of Fresnel reflection coefficients for air-film interface, for film-substrate interface and for substrate-air interface, respectively. The films show a high absorption coefficient value $\left(\approx 10^{6} \mathrm{~cm}^{-}\right.$ ${ }^{1}$ ), which can be used as an absorber layer in solar cells. The results reveal further that the absorption coefficient decreases with increasing copper concentration. Moreover, the absorption value suddenly decreases at the absorption edge, which is observed to shift to higher energy as the $\mathrm{Cu}$ doping level increases. The optical band -gap energy of nanostructured $\mathrm{Cu}$ doped film with the variety of $\mathrm{Cu}$ contents is estimated using Tauc's model $[35,36]$ : 
$(\alpha h v)^{1 / n}=\alpha_{0}\left(h v-E_{g}\right)$

where $\alpha_{o}$ is constant and the value of the exponent $n$ represents the direct $(n=1 / 2)$ [37]. The Tauc's relation is represented in Fig. 8 by $(\alpha h v)^{2}$ versus $(h v)$. The linear part of the Tauc's plot is extrapolated to $(\alpha h v)^{2}=0$. The optical band gap energy is determined from the intersection of the extrapolated line with $(\alpha h v)^{2}=0$. The obtained values for nanocrystalline undoped and $\mathrm{Cu}$ doped $\mathrm{CdTe}$ film is tabulated in Table 2. Obviously, the optical band gap energy of undoped CdTe film ( $E_{g}^{\text {opt }}=1.485$ $\mathrm{eV})$ is in accordance with the published value $\left(E_{g}^{o p t} \approx 1.49 \mathrm{eV}\right)$ [1]. Moreover, it is observed that the optical band gap energy increases with the increase of $\mathrm{Cu}$ doping level in CdTe lattice, which may be related to the Burstein-Moss effect. This effect is corresponding to degenerate doping semiconductors, in which the Fermi level lies inside the conduction band. According to the Burstein-Moss effect, as the $\mathrm{Cu}$ doping increases into CdTe, the electron carrier density of states of the conduction band edge increases. Therefore, the energy band gap increases with increasing the $\mathrm{Cu}$ doping level when the electrons are excited from the maximum edge of the valance band to the conduction band above the Fermi level since all the states below the Fermi level are occupied. This effect is also reported for the increase of energy band gap in Mo doped CdTe films [23] and Mo doped CdO films [38].

It is worth mentioning that, the optical constants, such as the refractive index and extinction coefficient, of semiconducting materials are essential optoelectronic parameters for designing the solar cell and photovoltaic devices. The refractive index of semiconductor thin films was calculated with different methods [39-44]. In this context, the refractive index of nanostructured $\mathrm{Cu}$ doped $\mathrm{CdTe}$ thin film is calculated by using Swanepoel method [45], then latter improved by Manifacier et al. [46]. This method is based on the suppression of the observed interference patterns in the transmittance spectra by constructing envelope curves around maxima and minima 
transmittance. The detailed process of this method has been described elsewhere [47,48]. The envelope of $\mathrm{Cu}$ doped CdTe:10 film is displayed in Fig. 9. The

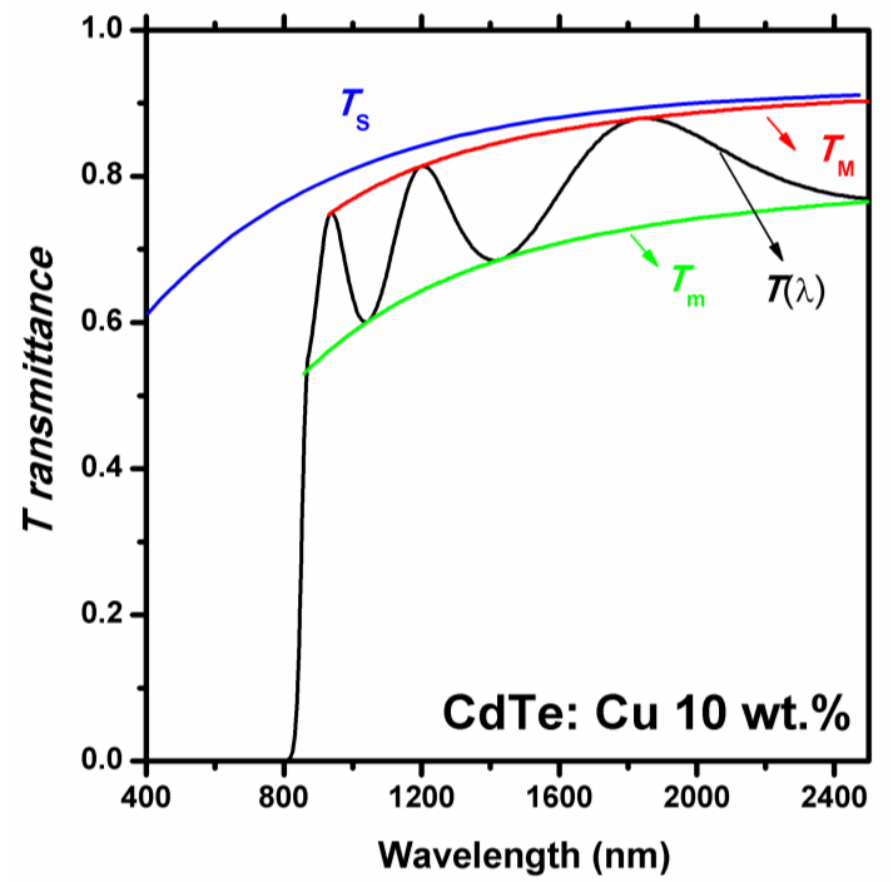

Fig. 9 The envelope of the transmittance curve of the CdTe:10 film.

spectral variation of refractive index of nanostructured $\mathrm{Cu}$ doped $\mathrm{CdTe}$ films is shown in Fig. 10. The figure shows a normal dispersion behavior for the spectral variation of refractive index of the undoped and $\mathrm{Cu}$ doped $\mathrm{CdTe}$ nanostructured films. It is important to note that as the $\mathrm{Cu}$ doping level increases, the overall behavior of the refractive index decreases. This decrease in refractive index is related to the observed increase in optical band gap energy with increasing $\mathrm{Cu}$ doping level, which is inversely correlated through different empirical models [49-51]. Lorentz-Lorenz quation relates the refractive index directly with the polarizability [52]. The substitution of $\mathrm{Cd}$ of larger atomic radius $(1.61 \AA)$ by $\mathrm{Cu}$ of smaller atomic radius (1.45 $\AA$ ) raises the density and thus diminishes the polarizability. 


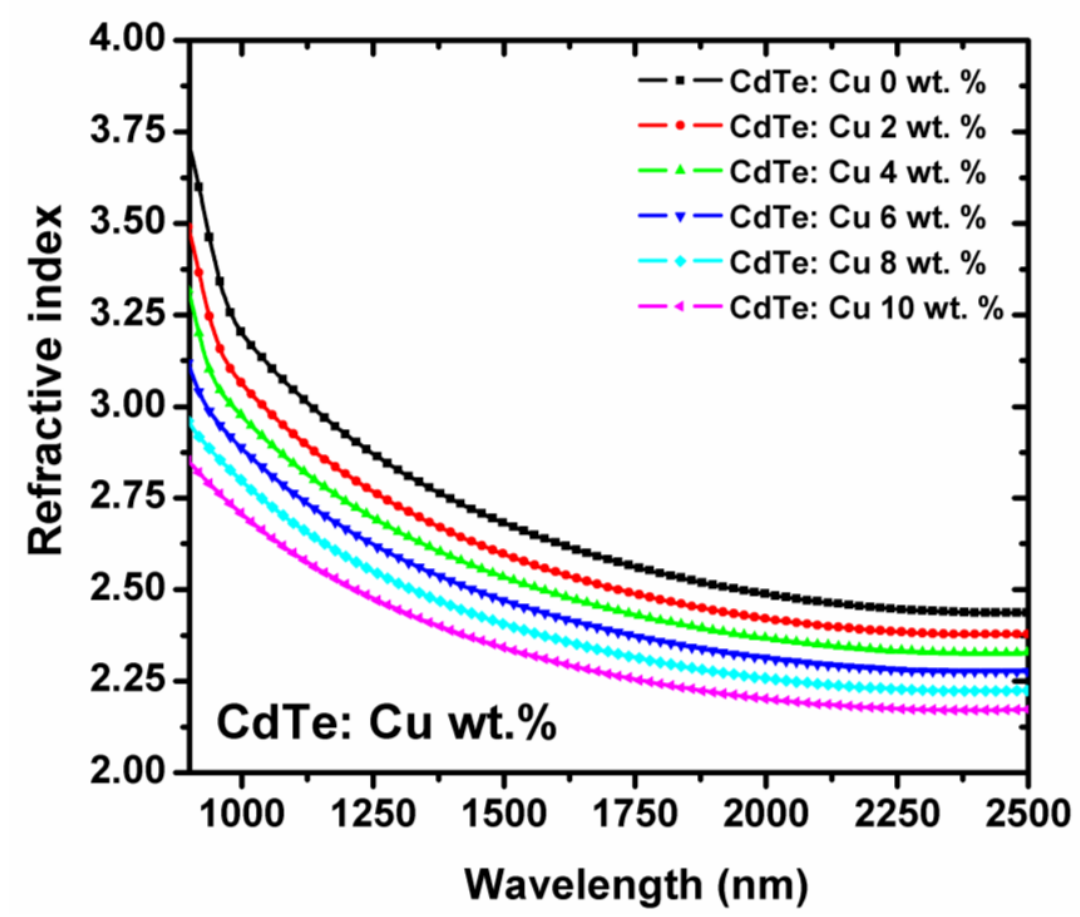

Fig. 10 The spectral dependence of the refractive of pure and $\mathrm{Cu}$ doped $\mathrm{CdTe}$ film with different $\mathrm{Cu}$ concentrations.

Accordingly, the decrease in the refractive index with the increase of $\mathrm{Cu}$ doping level is due to the decrease in the polarizability. On the other hand, the increase of the crystallinity and the grain size of CdTe film with the increase of the $\mathrm{Cu}$ concentration may also be another reason for the decrease in refractive index [53]. The extinction coefficient $(\mathrm{k})$ of $\mathrm{CdTe}$ and $\mathrm{Cu}$ doped $\mathrm{CdTe}$ films is determined from the following equation $\alpha=4 \pi k / \lambda$ [54]. The spectral behavior of the excitation coefficient of undoped and $\mathrm{Cu}$ doped $\mathrm{CdTe}$ nanocrystalline films is displayed in Fig. 11. It is can be seen that, the extinction coefficient drastically dropped to lowest value at the strong absorption region that is due to the total absorption of the incident photons at the fundamental absorption edge. The figure further shows that the overall extinction coefficient decreases with the increase of the $\mathrm{Cu}$ doping level. 


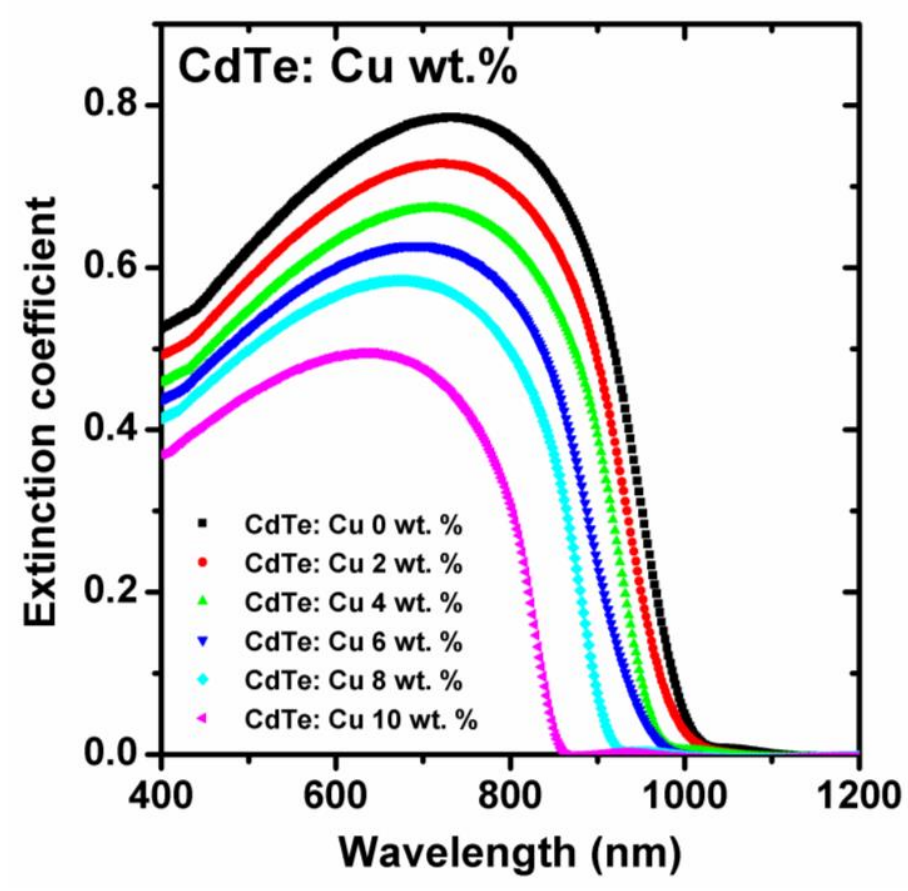

Fig. 11 The spectral variation of $\mathrm{k}$ for $\mathrm{Cu}$ doped films with various $\mathrm{Cu}$ doping level.

\subsection{Electrical properties}

The room temperature carrier concentration, carrier type and carrier mobility of undoped and $\mathrm{Cu}$ doped $\mathrm{CdTe}$ nanostructured films with different $\mathrm{Cu}$ concentrations were determined by Hall effect measurement. It can be seen that these films have ptype conduction behavior, which is determined by the sign of the positive Hall coefficient. Fig. 12 depicts the room temperature values of Hall mobility $\mu_{H}$, carrier concentrations $n_{H}$ and resistivity $\rho$ of nanostructured undoped and $\mathrm{Cu}$ doped $\mathrm{CdTe}$ film with various $\mathrm{Cu}$ doping levels. The results show that as $\mathrm{Cu}$ increases from 0 wt. $\%$ to $10 \mathrm{wt}$. $\%$, the carrier concentration and the Hall mobility increase from $7.20 \times 10^{18} \mathrm{~cm}^{-3}$ to $33.75 \times 10^{18} \mathrm{~cm}^{-3}$ and from $14.08 \mathrm{~cm}^{2} \mathrm{Vs}^{-1}$ to $83.19 \mathrm{~cm}^{2} \mathrm{Vs}^{-1}$, respectively. The increase in Hall mobility and carrier concentration with $\mathrm{Cu}$ doping 


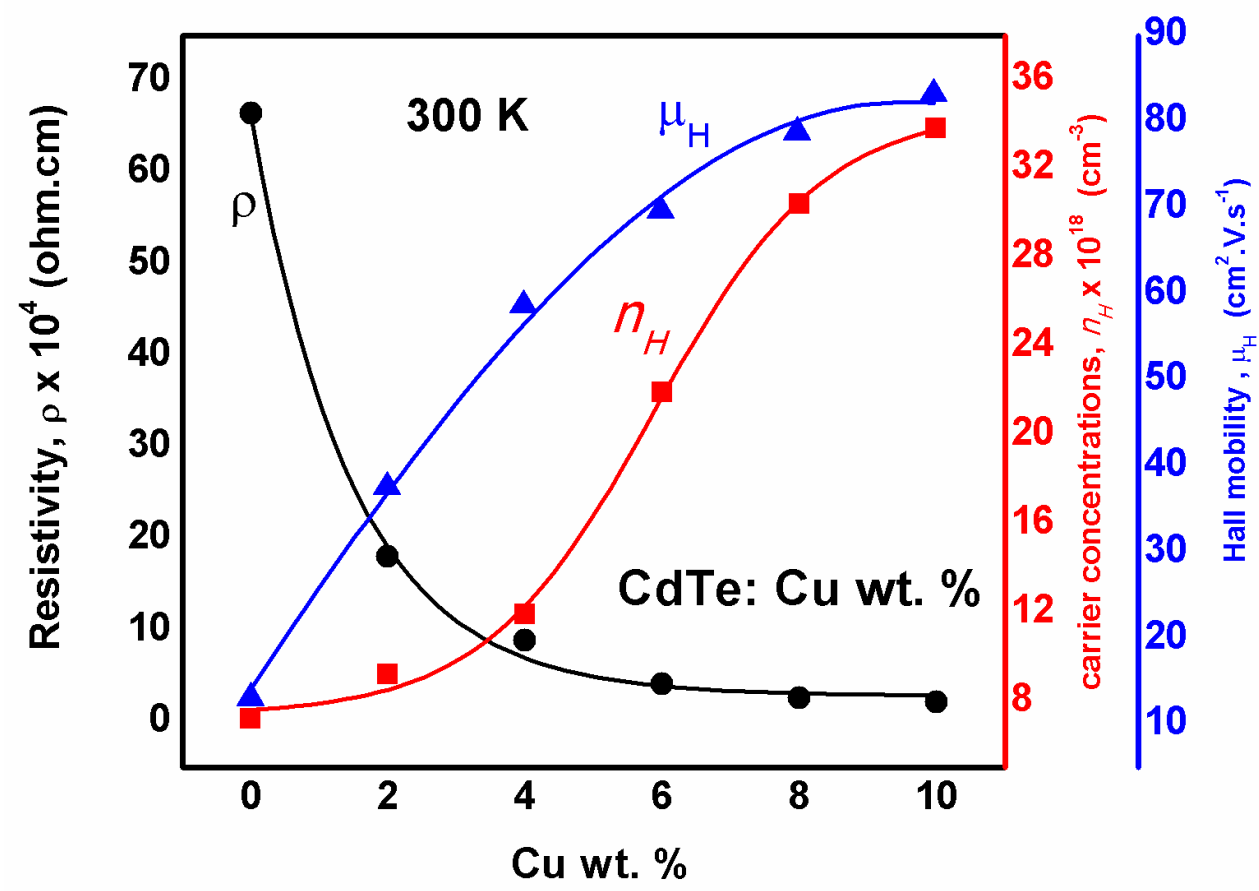

Fig. 12 The Hall mobility $\mu_{H}$, carrier concentrations $n_{H}$ and resistivity $\rho$ at room temperature of nanostructured undoped and $\mathrm{Cu}$ doped $\mathrm{CdTe}$ film with various $\mathrm{Cu}$ doping levels.

is attributed to the decrease in the scattering of the grain boundary, which is due to the increase in grain size originated with the rise in $\mathrm{Cu}$ doping level. This can be confirmed from AFM measurements, where the lack of any voids or carks is remarked due to the improved crystallinity and the absence of defects in the films. Thus, as a result of the enhanced mobility, the resistivity of undoped and $\mathrm{Cu}$ doped $\mathrm{CdTe}$ thin films at room temperature decreased with the increase of $\mathrm{Cu}$ doping level from 66.38 x $10^{-4}$ ( $\Omega . \mathrm{cm}$ ) for CdTe:0 wt.\% to $2.93 \times 10^{-4}(\Omega . \mathrm{cm})$ for CdTe:10 wt. \%. This is in accordance with the reported huge reductions in the electrical resistivity of CdTe single crystals [55-58] and thin films $[13,60]$ upon incorporated tiny amount of $\mathrm{Cu}$. Thus, upon the increase of $\mathrm{Cu}^{2+}$ ions concentration instead of the $\mathrm{Cd}^{2+}$ ions concentration, more electrons (free carrier concentration) are promoted to the conduction band, resulting in a further decrease in resistivity. This explains the 
observed decrease in resistivity with increasing $\mathrm{Cu}$ content. In order to investigate the mechanism of conductivity, the temperature dependent dc conductivity measurements (in the form of Ln $\sigma$ versus 1000/T representations) of nanocrystalline undoped and $\mathrm{Cu}$ doped $\mathrm{CdTe}$ films with different $\mathrm{Cu}$ concentrations were analysed and presented in Fig. 13. Obviously, a non-linear temperature-dependent conductivity behavior is observed. Further, it was observed that the electrical dc conductivity of nanocrystalline undoped and $\mathrm{Cu}$ doped $\mathrm{CdTe}$ films increases exponentially with increasing temperature. As a consequence, the results exhibit semiconducting like behavior for all $\mathrm{Cu}$ doped $\mathrm{CdTe}$ films over the entire measurement temperature region from $300 \mathrm{~K}$ to $450 \mathrm{~K}$. Additionally, the dc conductivity increases with the increase of the $\mathrm{Cu}$ doping level in the $\mathrm{CdTe}$ film which is attributed to the increase in the grain size, thereby reducing grain boundary scattering. Accordingly, it can be concluded that by increasing the $\mathrm{Cu}$ doping level in the $\mathrm{CdTe}$ film, as the conductivity increases, the performance of the CdTe layer in the solar cell can be improved. Similar behaviour has been reported for $\mathrm{Cu}$ doped $\mathrm{CdSe}$ films [61], $\mathrm{Cu}$ doped $\mathrm{CdTe}$ films [27] and Ag-CdSe films [62]. Table 2 illustrates the decreases in the resistivity and the increase of the electrical conductivity at room temperature as the $\mathrm{Cu}$ doping increases. the Furthermore, according to the Arrhenius relationship $\sigma=\sigma_{o} \exp \left(-E_{a} / k T\right)$, where $E_{a}$ is the thermal activation energy and $k$ is the Boltzmann constant, the results reveal two different regions with two slops at low and high distinct temperature ranges, which indicates two conduction mechanisms for the carrier transport in nanostrcutured undoped and $\mathrm{Cu}$ doped $\mathrm{CdTe}$ films. 


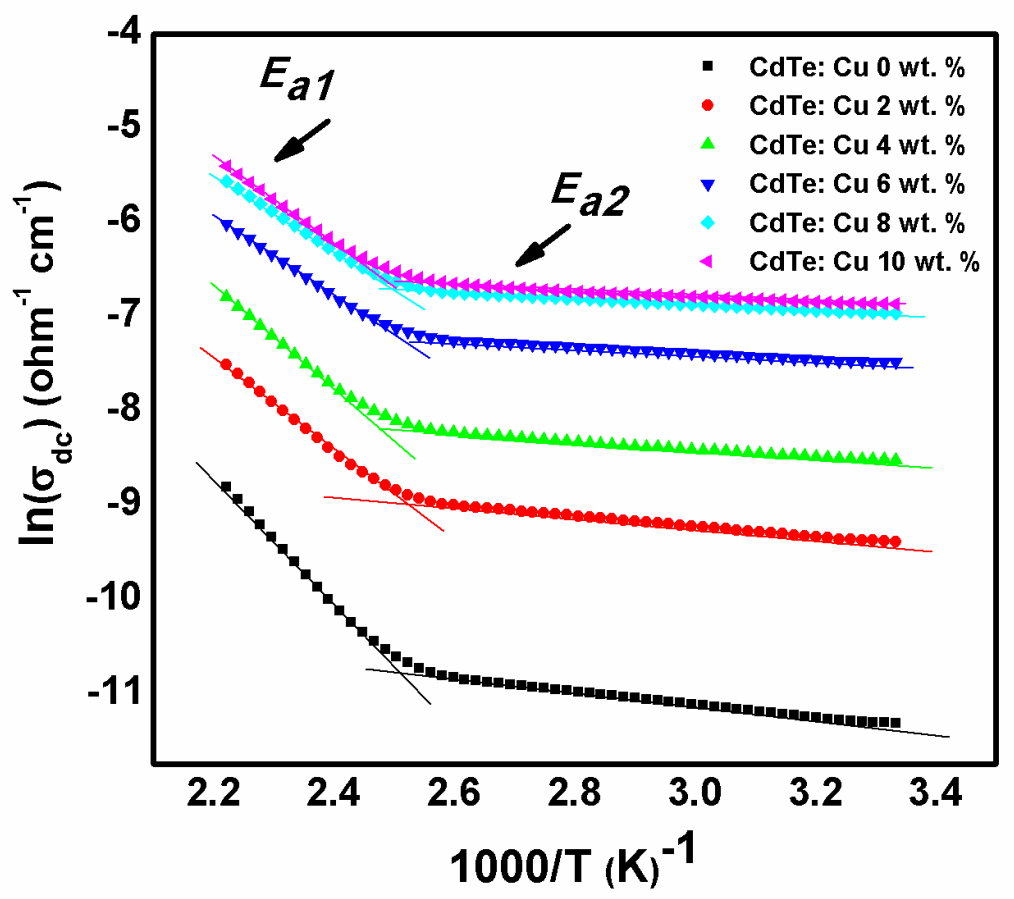

Fig. $13 \ln \sigma_{\mathrm{dc}}$ versus 1000/T of undoped and $\mathrm{Cu}$ doped CdTe nanostructure film with various $\mathrm{Cu}$ doping levels.

Consequently, the high temperature activation energy (387 - $450 \mathrm{~K}) E_{a 1}$ and low temperature activation energy $(300-386 \mathrm{~K}) E_{a 2}$ of undoped and $\mathrm{Cu}$ doped $\mathrm{CdTe}$ films are evaluated based on the slope of the curves in the two regions using the following equation: $\sigma=\sigma_{1} \exp \left(-E_{a 1} / k T\right)+\sigma_{2} \exp \left(-E_{a 2} / k T\right)$, where $\sigma_{1}$ and $\sigma_{2}$ are the preexponential factors. The values of $E_{a 1}$ and $E_{a 2}$ of undoped and $\mathrm{Cu}$ doped CdTe films are summarized in Table 1 . The low temperature activation energy $\left(E_{a 2}\right)$ may be due to the low temperature conductivity by hopping of carriers between the localized states above the edge of the valence band to the extended states in the conduction band, while in the high temperature region, the normal type of band conduction in extended states can be considered to be the main mode of the conduction mechanism. On the other hand, it is found that the low temperature activation energy $E_{a 2}$ decreases as the $\mathrm{Cu}$ content increases from $58 \mathrm{meV}(\mathrm{CdTe}: 0)$ to $25 \mathrm{meV}(\mathrm{CdTe}: 10)$. Also, the high temperature activation energy $E_{a 1}$ is found to decrease with the increase of the $\mathrm{Cu}$ doping level from $578 \mathrm{meV}(\mathrm{CdTe}: 0)$ to $320 \mathrm{meV}(\mathrm{CdTe}: 10)$. The decrease in 
activation energy is attributed to the observed increase in crystallinity and decrease in defects. Different groups similarly reported the decrease in activation energy with increasing dopant concentration $[63,64]$. Besides, at all temperatures up to room temperature, the dependence of $\ln \sigma$ and $T^{-1 / 4}$ in the undoped and $\mathrm{Cu}$ doped $\mathrm{CdTe}$ nanocrystalline film is checked, which is an excellent tool for examining the hopping conduction mechanism, particularly the Mott's variable range hopping conduction model (VRH). It is worth mentioning that VRH in semiconductors is expected to dominate at appropriate low temperatures [61]. Therefore, the low temperature dependence of the conductivity of undoped and $\mathrm{Cu}$ doped $\mathrm{CdTe}$ nanostructured films can be analyzed based on Mott's variable range hopping conduction model (VRH) [65]:

$\sigma T^{1 / 2}=\sigma_{0} \exp \left(-\left(T_{0} / T\right)^{1 / 4}\right)$

where Mott temperature $T_{o}$ is given by [66]

$$
T_{\mathrm{o}}=C_{\mathrm{o}}\left(\frac{\alpha^{3}}{k N\left(E_{f}\right)}\right)
$$

where $N\left(E_{F}\right)$ is the density of states at the Fermi level, $\alpha$ is the exponential decay coefficient of the localized states wave function $\left(\approx 0.124 \AA^{-1}[67]\right)$ and $\mathrm{C}_{0}(\approx 24 / \Pi)$ is the constant of proportionality. The observed linear low temperature dependence of the conductivity in $\ln \left(\sigma \mathrm{T}^{1 / 2}\right)$ and $\left(\mathrm{T}^{-1 / 4}\right)$ representation of undoped and $\mathrm{Cu}$ doped CdTe nanocrystalline films (see Fig. 14), indicating a dominant variable range hopping (VRH) conduction mechanism where the low temperature conduction 


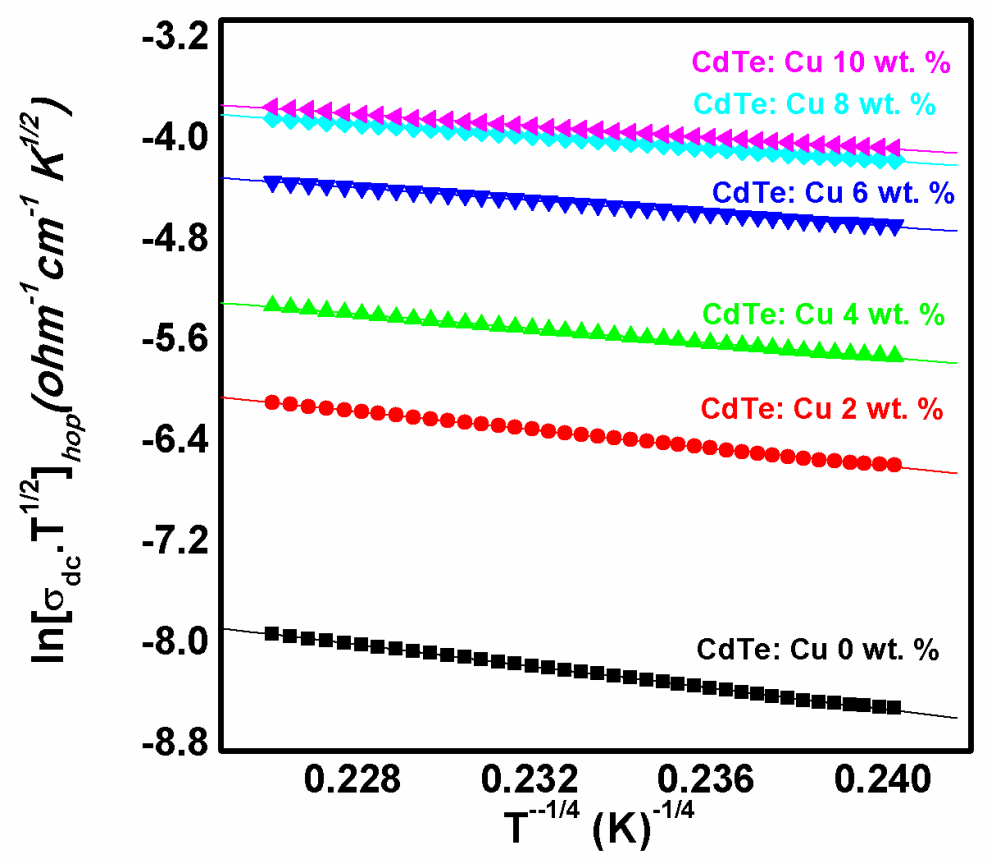

Fig. $14 \ln \left(\sigma_{\mathrm{dc}} \mathrm{T}^{1 / 2}\right)$ versus $\mathrm{T}^{-1 / 4}$ of undoped and $\mathrm{Cu}$ doped $\mathrm{CdTe}$ nanostructure film with various $\mathrm{Cu}$ doping levels.

mechanism is ascribed to hopping of free carriers between localized states. Furthermore, the hopping distance $R$, the hopping energy $W$ and the the density of states at the Fermi level $N\left(E_{F}\right)$ are calculated at room temperature $(300 \mathrm{~K})$ for undoped and $\mathrm{Cu}$ doped $\mathrm{CdTe}$ nanostructured films from the linear correlation slope in Fig. 12 and are summarized in Table 2 [61]. Apparently, as $\mathrm{Cu}$ doping increases from CdTe:0 to CdTe:10 wt. \%, the density of state increases from $1.178 \times 10^{17} \mathrm{eV}^{-1} \mathrm{~cm}^{-3}$ to $14.28 \times 10^{17} \mathrm{eV}^{-1} \mathrm{~cm}^{-3}$. Also, it was found that the values of $\alpha R(734.51(\mathrm{CdTe}: 0)-$ $60.58(\mathrm{CdTe}: 10))$ are greater than 1 and the values of $W(0.053(\mathrm{CdTe}: 0)-0.029$ $(\mathrm{CdTe}: 10))$ are greater than the thermal energy $(0.0259 \mathrm{eV})$ which are essential conditions for the above mentioned factors to be consistent with the Mott's VRH $[68,69]$. Finally, $\alpha R>1$ indicates that the carries are more localized in the trap states.

Table 2 The optical band gap energy and electrical properties of pure and $\mathrm{Cu}$ doped CdTe films. 


\begin{tabular}{|c|c|c|c|c|c|c|c|c|c|c|c|c|}
\hline \multirow[t]{2}{*}{$\begin{array}{c}\text { CdTe:Cu } \\
\text { (wt.\%) }\end{array}$} & \multirow[t]{2}{*}{$\begin{array}{l}E_{g}^{o p t} \\
(\mathrm{eV})\end{array}$} & \multirow[t]{2}{*}{$\begin{array}{l}E_{a 1} \\
(e V)\end{array}$} & \multirow[t]{2}{*}{$\begin{array}{c}E_{a 2} \\
(\mathrm{eV})\end{array}$} & \multirow[t]{2}{*}{$\begin{array}{c}\rho \rho 10^{4} \\
(\Omega . c \mathrm{~cm})\end{array}$} & \multirow[t]{2}{*}{$\begin{array}{c}\sigma_{d c} \times 10^{-6} \\
\left(\Omega^{1} \cdot \mathrm{cm}^{-1}\right)\end{array}$} & \multirow[t]{2}{*}{$\begin{array}{c}\mu_{H} \\
\mathrm{~cm}^{2} / V . s\end{array}$} & \multirow[t]{2}{*}{$\begin{array}{c}n_{H} \times 10^{1} \\
8 \\
\left(\mathrm{~cm}^{3}\right) \\
\end{array}$} & \multirow{2}{*}{$\begin{array}{c}T_{o} \\
x 10^{5} \\
(K) \\
300 \mathrm{~K}\end{array}$} & \multirow[t]{2}{*}{$\begin{array}{c}N\left(E_{f}\right) \times 10^{l} \\
7 \\
\left(\mathrm{eV}^{-1} \mathrm{~cm}^{-3}\right)\end{array}$} & \multirow[t]{2}{*}{$\begin{array}{c}W \\
(e V)\end{array}$} & \multirow[t]{2}{*}{$\begin{array}{c}R \times 10^{-4} \\
(\mathrm{~cm})\end{array}$} & \multirow[t]{2}{*}{$\alpha R$} \\
\hline & & & & & & & & & & & & \\
\hline 0 & $\begin{array}{l}1.48 \\
5\end{array}$ & $\begin{array}{c}0.57 \\
8\end{array}$ & $\begin{array}{c}0.05 \\
8\end{array}$ & 66.5 & 1.50 & 13.05 & 7.2 & 33.82 & 1.178 & $\begin{array}{c}0.05 \\
3\end{array}$ & 5.923 & 734 \\
\hline 2 & $\begin{array}{l}1.50 \\
8\end{array}$ & $\begin{array}{c}0.42 \\
9\end{array}$ & $\begin{array}{c}0.04 \\
7\end{array}$ & 18.1 & 5.52 & 37.55 & 9.2 & 17.30 & 2.302 & $\begin{array}{c}0.04 \\
5\end{array}$ & 3.03 & 375 \\
\hline 4 & $\begin{array}{l}1.52 \\
3\end{array}$ & $\begin{array}{c}0.42 \\
4\end{array}$ & $\begin{array}{c}0.03 \\
4\end{array}$ & 8.90 & 10.23 & 58.65 & 11.9 & 6.75 & 5.899 & $\begin{array}{c}0.03 \\
6\end{array}$ & 1.183 & 146 \\
\hline 6 & $\begin{array}{l}1.56 \\
5\end{array}$ & $\begin{array}{c}0.35 \\
4\end{array}$ & $\begin{array}{c}0.02 \\
8\end{array}$ & 4.10 & 24.39 & 69.63 & 21.9 & 4.09 & 9.738 & $\begin{array}{c}0.03 \\
1\end{array}$ & 0.716 & 88 \\
\hline 8 & $\begin{array}{l}1.60 \\
1\end{array}$ & $\begin{array}{c}0.34 \\
2\end{array}$ & $\begin{array}{c}0.02 \\
6\end{array}$ & 2.60 & 38.46 & 78.74 & 30.4 & 3.36 & 11.833 & 0.03 & 0.589 & 73 \\
\hline 10 & $\begin{array}{l}1.68 \\
3 \\
\end{array}$ & $\begin{array}{c}0.30 \\
6 \\
\end{array}$ & $\begin{array}{c}0.02 \\
5 \\
\end{array}$ & 2.20 & 45.54 & 83.19 & 33.8 & 2.78 & 14.279 & $\begin{array}{c}0.02 \\
9 \\
\end{array}$ & 0.489 & 60 \\
\hline
\end{tabular}

\section{Summary}

To summarize, pure and $\mathrm{Cu}$ doped $\mathrm{CdTe}$ nanostructure thin films were deposited by electron beam evaporation technique on glass substrates. The XRD investigation shows that all the films are cubic zinc blende structure. It was found that the average crystallite size increases from $16 \mathrm{~nm}$ to $18 \mathrm{~nm}$, while the microstrian decreases from $1.2 \times 10^{-3}\left(\mathrm{Lin} / \mathrm{m}^{2}\right)$ to $0.70 \times 10^{-3}\left(\mathrm{Lin} / \mathrm{m}^{2}\right)$ as the $\mathrm{Cu}$ doping level increases from $0 \mathrm{wt}$. $\%$ to 10 wt. \% . The average transmittance of $\mathrm{Cu}$ doped CdTe films in the near infrared region was found to vary from $78 \%$ to $82 \%$, which can be used as an n-type window layer for photovoltaic solar cell applications. The optical band gap energy of $\mathrm{Cu}$ doped CdTe films increases from $1.485 \mathrm{eV}$ to $1.683 \mathrm{eV}$ as the $\mathrm{Cu}$ concentration increases from 0 wt. $\%$ to $10 \mathrm{wt} . \%$. The optical analysis of the spectral behavior of the optical constants of $\mathrm{Cu}$ doped $\mathrm{CdTe}$ films shows that the refractive index and extinction coefficient decrease with the increase of the $\mathrm{Cu}$ doping in $\mathrm{CdTe}$ matrix.

It is found that the resistivity decreases and the dc electrical conductivity increases at room temperature with increasing $\mathrm{Cu}$ doping. Additionally, it is observed that the conductivity temperature dependent of nanostrcutured undoped and $\mathrm{Cu}$ doped $\mathrm{CdTe}$ films shows two conduction mechanisms of the carrier transport. Mott's variable range hopping conduction mechanism model (VRH) is used to interpret the low 
temperature dependence of the conductivity, the behaviour of hopping distance $R$, the hopping energy $W$ and the the density of states at the Fermi level $N\left(E_{F}\right)$ of undoped and $\mathrm{Cu}$ doped $\mathrm{CdTe}$ nanostructured films. Finally, $\mathrm{p}$ - type conduction behavior is observed from Hall effect measurements for all the films. Besides, the carrier concentration and Hall mobility increase with increasing of $\mathrm{Cu}$ doping level. It can be concluded that as the $\mathrm{Cu}$ doping level increases, the conductivity increases, thereby improving the performance of the CdTe absorber layer in the solar cell structure.

\section{Acknowledgments}

The authors extend their appreciation to the Deputyship for Research \& Innovation, Ministry of Education in Saudi Arabia for funding this research work through the project number 1527110410 .

\section{References}

[1] M. C. Schlamp, X. G. Peng, and A. P. Alivisators, J. Appl. Phys. 82, 5837 (1997).

[2] P. C. Sarmah and A. Rahman, "Current-voltage characteristics of Ag, Al, Ni-(n) CdTe junctions," Bulletin of Materials Science, vol. 24, no. 4, pp. 411-414, 2001.

[3] S. T. Sundari, V. Swaminathan, A. K. Tyagi, and T. Mahalingam,"Microstructural studies of oxygen irradiated CdTe thin films," Physica Status Solidi (A), vol. 177, no. 2, pp. 495-502, 2000.

[4] C. Polop, I. Mora-Sero, C. Munuera, J. Garcia de Andres, V. Munoz-Sanjose, and C. Ocal, Acta Mater. 54, 4285 (2006).

[5] M. Niraula, K. Yasuda, T. Ishiguro, Y. Kawauchi, H.Morishita, and Y. Agata, "Metal-organic vapor-phase epitaxy growth and characterization of thick (100) CdTe layers on (100) GaAs and (100) GaAs/Si substrates," Journal of Electronic Materials, vol. 32, no. 7, pp. 728-732, 2003.

[6] N. Lovergine, P. Prete, L. Tapfer, F.Marzo, and A.M.Mancini, "Hydrogen transport vapour growth and properties of thick CdTe epilayers for RT X-ray detector applications," Crystal Research and Technology, vol. 40, no. 10-11, pp. 1018-1022, 2005.

[7] P. Banerjee, R. Ganguly, and B. Ghosh, Appl. Surf. Sci. 256, 213 (2009). 
[8] K. M. Garadkar, S. J. Pawar, P. P. Hankare, and A. A. Patil, J. Alloys Compd. 491, 77 (2010).

[9] F. de Moure-Flores, J. G. Qui nones-Galv_an, A. Guill_en-Cervantes, J. S. Arias-

Cer_on, A. Hern_andez-Hern_andez, J. Santoyo-Salazar, J. Santos-Cruz, S. A.

May_en-Hern_andez, M. de la L. Olvera, J. G. Mendoza- Alvarez, M. Mel_endez-

Lira, and G. Contreras-Puente, J. Cryst. Growth 386, 27 (2014).

[10] V. Kosyak, A. Opanasyuk, P. M. Bukivskij, and Yu. P. Gnatenko, J. Cryst.

Growth 312, 1726 (2010).

[11] R. Raj Singh, D. Painuly, and R. K. Pandey, Mater. Chem. Phys. 116, 261(2009).

[12] E. R. Shaaban, N. Afify, and A. El Taher, J. Alloys Compd. 482, 400 (2009).

[13] K. Punitha, R. Sivakumar, C. Sanjeeviraja, Vasant Sathe, and V. Ganesan, Journal of Applied Physics 116, 213502 (2014)

[14] C. Doroody, K.S. Rahman, S.F. Abdullah, M.N. Harif, H.N.Rosly, S.K. Tiong, N. Amin, Temperature difference in close spaced sublimation (CSS) growth of CdTe thin film on ultrathin glass substrate. Results Phys. 18, 103213 (2020)

[15] M.A. Islam, S.F. wan Muhamad Hatta, H. Misran, M. Akhtaruzzaman, N. Amin, Influence of oxygen on structural and optoelectronic properties of CdS thin film deposited by magnetron sputtering technique. Chin. J. Phys. 67, 170-179 (2020) [16] Z. Xie, Y. Sui, J. Buckeridge, C.R.A. Catlow, T.W. Keal, P. Sherwood, A. Walsh, M.R. Farrow, D.O. Scanlon, S.M. Woodley, A.A. Sokol, Donor and acceptor characteristics of native point defects in GaN. J. Phys. D Appl. Phys. 52, 335104 (2019)

[17] B. Choudhury, M. Dey, A. Choudhury, Shallow and deep trap emission and luminescence quenching of $\mathrm{TiO} 2$ nanoparticles on $\mathrm{Cu}$ doping. Appl. Nanosci. 4, 499506 (2014)

[18] S.L. Himanshu, A. Patel, M.D. Thakur, M.S. Kannan, Dhaka, Analysis of different annealing conditions on physical properties of Bi doped CdTe thin films for potential absorber layer in solar cells. Sol. Energy 199, 772-781 (2020)

[19] O. Vigil-Galan, E. Sa'nchez-Meza, J. Sastre-Hernandez, F. Cruz-Gandarilla, E. Marin, G. Contreras-Puente, E. Saucedo, C.M. Ruiz, M. Tufino-Vela'zquez, A. Calderon, Study of the physical properties of Bi doped CdTe thin films deposited by close space vapour transport. Thin Solid Films 516, 3818-3823 (2008)

[20] U. Alver, E. Bacaksiz, E. Yanmaz, Structural, magnetic and optical properties of Co-diffused CdTe thin films. J. Alloys Compd. 456, 6-9 (2008) 
[21] K.A. Aris, K.S. Rahman, A.M. Ali, B. Bais, I.B. Yahya, Md. Akhtaruzzaman, H. Misran, S.F. Abdullah, M.A. Alghoul, N. Amina, A comparative study on thermally and laser annealed copper and silver doped CdTe thin film solar cells. Sol. Energy 173, 1-6 (2018)

[22] Sh.U. Yuldashev, Y.B. Hou, J.H. Leem, C.K. Kang, S.H. Park, T.W. Kang, T.W. Kim, Effects of hydrogenation and annealing on the shallow donor-band recombination in Indoped CdTe epitaxial layers grown on p-CdTe (211) substrates. J. Phys. Chem. Solids 61, 711-718 (2000)

[23] T. Manimozhi, T. Logu, J. Archana, M. Navaneethan, K. Sethuraman, and K. Ramamurthi, Enhanced photo-response of CdTe Thin film via Mo doping prepared using electron beam evaporation technique, J Mater Sci: Mater Electron (2020) 31:21059-21072

[24] B. Monemar, E. Molva, and L. Si Dang, Phys. Rev. B 33, 1134 (1986).

[25] M. El-Hagary, S.H. Moustafa, H. Hashem, E.R. Shaaban, M. Emam-Ismail, Influences of $\mathrm{Mn}$ doping on the microstructural, semiconducting, and optoelectronic properties of $\mathrm{HgO}$ nanostructure films, J AM CERAM SOC 102, (2019)4737-4747

[26] Cho M. $-\mathrm{H}$, Ko D $-\mathrm{H}$, Jeong K, Whangbo S W, Whang C N, Cho S J, Growth stage of crystalline $\mathrm{Y}_{2} \mathrm{O}_{3}$ film on $\mathrm{Si}(100)$ grown by an ionized cluster beam deposition. J. Appl. Phys. 1999; 85: 2909-2914.

[27] Manimozhi Thangaraju, Archana Jayaram, Ramamurthi Kandasamy, Structural, morphological, optical and electrical properties of e-beam deposited nanocrystalline CdTe:Cu alloy thin films from mechanical alloyed samples, Appl. Surf. Sci. 449, 15 (2018) 2-9

[28] Dehimi M, Touam T, Chelouche A, Boudjouan F, Djouadi D, Solard J, Fischer A, Boudrioua A and Doghmane A 2015 Effects of low Ag doping on physical and optical waveguide properties of highly oriented sol-gel zno thin films Adv. Cond. Matter Phy. 2015 1-10

[29] T. Saidani, M. Zaabat, M.S. Aida, B. Boudine, Effect of Copper Doping on the Photocatalytic Activity

of ZnO Thin Films Prepared by Sol-gel Method, Superlattices Microstruct., 88 (2015) 315-322.

[30] M. I. Amer, S. H. Moustafa, M. El-Hagary, Materials Chemistry and Physics 248, art. no. 122892 (2020). 
[31] Ligang Ma, Xiaoqian Ai, Xiaoshan Wu, Effect of substrate and Zn doping on the structural, optical and electrical properties of CdS thin films prepared by CBD method, Journal of Alloys and Compounds 691 (2017) 399e406

[32] J. Zhou, X. Wu, G. Teeter, B. To, Y. Yan, R. Dhere, T. Gessert, CBD Cd ${ }_{1 \_x} Z_{x} S$ thin films and their application in CdTe solar cells, Phys. Status Solidi (b) 241 (2004) $775 \mathrm{e} 778$.

[33] N. E. Makori*, I. A. Amatalo, P. M. Karimi, W. K. Njoroge, Optical and Electrical Properties of CdO: Sn Thin Films for Solar Cell Applications, International Journal of Optoelectronic Engineering 2014, 4(1) 11-15

[34] S. H. Wemple and J. A. Seman, Appl. Opt. 12 (1973) 2947

[35] J. Tauc, In: Optical properties of Solids Abeles F, editor Amsterdam NorthHolland (1969).

[36] E. A. Davis, N. F. Mott, Philos Mag. 22 (1970) 903.

[37] B.D. Viezbicke, S. Patel, B.E. Davis, D.P. Birnie III, physica status solidi (b) 252 (2015) 1700-1710.

[38] R. Kumeravel, S. Bhuvaneswari, K. Ramamurthi, V. Krishnakumar, Structural, optical and electrical properties of molybdenum doped cadmium oxide thin films prepared by spray pyrolysis method. Appl. Phys. A 109, 579-584 (2012)

[39] G. Jellison Jr, F. Modine, Appl. Phys. Lett. 69 (1996) 371-373.

[40] S. Jena, R.B. Tokas, S. Thakur, D.V. Udupa, Optik 185 (2019) 71-81.

[41] D. Minkov, J. Phy. D: Appl. Phy. 22 (1989) 1157.

[42] J. Gonzalez-Leal, E. Marquez, A. Bernal-Oliva, J. Ruiz-Perez, R. Jimenez-Garay, Thin Solid Films 317 (1998) 223- 227.

[43] M. Emam-Ismail, M. El-Hagary, E.R. Shaaban, S. Althoyaib, J. Alloys Compd. 529 (2012) 113-121.

[44] M. Emam-Ismail, E.R. Shaaban, M. El-Hagary, J. Alloys Compd. 663 (2016) $20-29$.

[45] R. Swanepoel, J. Phy. E: Scientific Instruments 16 (1983) 1214.

[46] J.C. Manifacier, J. Gasiot, J.P. Fillard, J. Phy. E 9 (1976) 1002.

[47] M. El-Hagary, M. Emam-Ismail, E. R. Shaaban, Optical properties of glasses (TeO2-GeO2-K2O) thin films co-doped with rare earth oxides $\mathrm{Sm} 2 \mathrm{O} 3 / \mathrm{Yb} 2 \mathrm{O} 3$, Journal of Alloys and Compounds 485 (1-2), 519-523.

[48] E. R. Shaaban, M. El-Hagary, M. Emam-Ismail, M. B. El-den, Optical band gap, refractive index dispersion and single-oscillator parameters of amorphous $\mathrm{Se}_{70} \mathrm{~S}_{30-} \mathrm{Sb}_{\mathrm{x}}$ semiconductor thin films, Philosophical Magazine, 91(12), 1679- 
1792 (2011).

[49] T. Moss, Proc. Phys. Soc. Sect. B, 63 (1950) 167.

[50] N. M. Ravindra, S. Auluck, and V. K. Srivastava, Phys. Status Solidi B 93 (1979) K155 .

[51] P. J. L. Herve and L. K. J. Vandamme, J. Appl. Phys. 77 (1995) 5476-5477.

[52] Elliott. The physics and chemistry of solids. Chichester: Wiley; 2000.

[53] K. Senthil, D. Mangalaraj, S.K. Narayandass, and S. Adachi, Mat. Sci. Eng. B, Vol. 78, pp. 53-58, 2000.

[54] E.R. Shaaban, M. El-Hagary, M. Emam-Ismail, A.M. Abd Elnaeim, S. H. Moustafa, Optical characterization of polycrystalline ZnSe1-xTex thin films using Variable Angle Spectroscopic Ellipsometry and Spectrophotmetery techniques, Materials Science in Semiconductor Processing- 2015 39, 735-741

[55] E. Kuc`ys, J. Jerhot, K. Bertulis, and V. Bariss, Phys. Status Solidi A 59(1), 9199 (1980).

[56] K. K. Chin, T. A. Gessert, and W. Su-Huai, paper presented at the $35^{\text {th }}$ IEEE Photovoltaic Specialists Conference (PVSC), Honolulu, Hawaii, 2010.

[57] Ma, S.-H. Wei, T. A. Gessert, and K. K. Chin, Phys. Rev. B 83(24), 245207 (2011).

[58] B. Biglari, M. Samimi, M. Hage-Ali, J. M. Koebel, and P. Siffert, J. Cryst. Growth 89(4), 428-434 (1988).

[59] R. Raj Singh, D. Painuly, and R. K. Pandey, Mater. Chem. Phys. 116, 261 (2009).

[60] A. Ali, N.A. Shah, A.K.S. Aqili, A. Maqsood, Investigation of Cu-containing low resistivity CdTe thin films deposited by the two-source evaporation technique. J. Semicond. Sci. Technol. 21 (2006) 1296-1302

[61] Kriti Sharma, Poonam, G. S. S. Saini, S. K. Tripathi, A comparative study of transport properties of copper doped cadmium selenide thin films at two dopant concentrations, Journal of Materials Science: Materials in Electronics (2018) 29:9596-9604

[62] Ramezan Sahebi , Mahmood Rezaei Roknabadi and Mohammad Behdani, Effect of Ag-doping on the structural, optical, electrical and photovoltaic properties of thermally evaporated Cadmium Selenide thin films, Mater. Res. Express 6 (2019) 126453 
[63] Ala J. Al-Douri, F. Y. Al-Shakily, Abdalla A. Alnajjar, andMaysoon F. A. Alias, The Role of Dopant Concentration on Conductivity and Mobility of CdTe Thin Films, Advances in Condensed Matter Physics, Volume 2011, Article ID 910967, 6 pages. [64] N. M. Megahid, M. M. Wakkad, E. K. H. Shokr, and N.M. Abass, "Microstructure and electrical conductivity of In doped CdS thin films," Physica B, vol. 353, no. 3-4, pp. 150-163, 2004.

[65] N.F. Mott, J. Non-Cryst. Solids 8, 191 (1972)

[66] N.F. Mott, E.A. Davis, Electronic Processes in Non-Crystalline Materials, 2nd edn. (Clarendon, Oxford, 1979)

[67] S. Ramchandar Rao, M. Nagabhooshanam, V.Hari Babu, Cryst. Res. Technol. 25, 55 (2006)

[68] T.G. Abdel-Malik, R.M. Abdel-Latif, A. Sawaby, S.M. Ahmed, J. Appl. Sci. Res. 4, 331 (2008)

[69] N.F. Mott, E.A. Davis, Philos. Mag. 22, 903 (1970) 
Figures
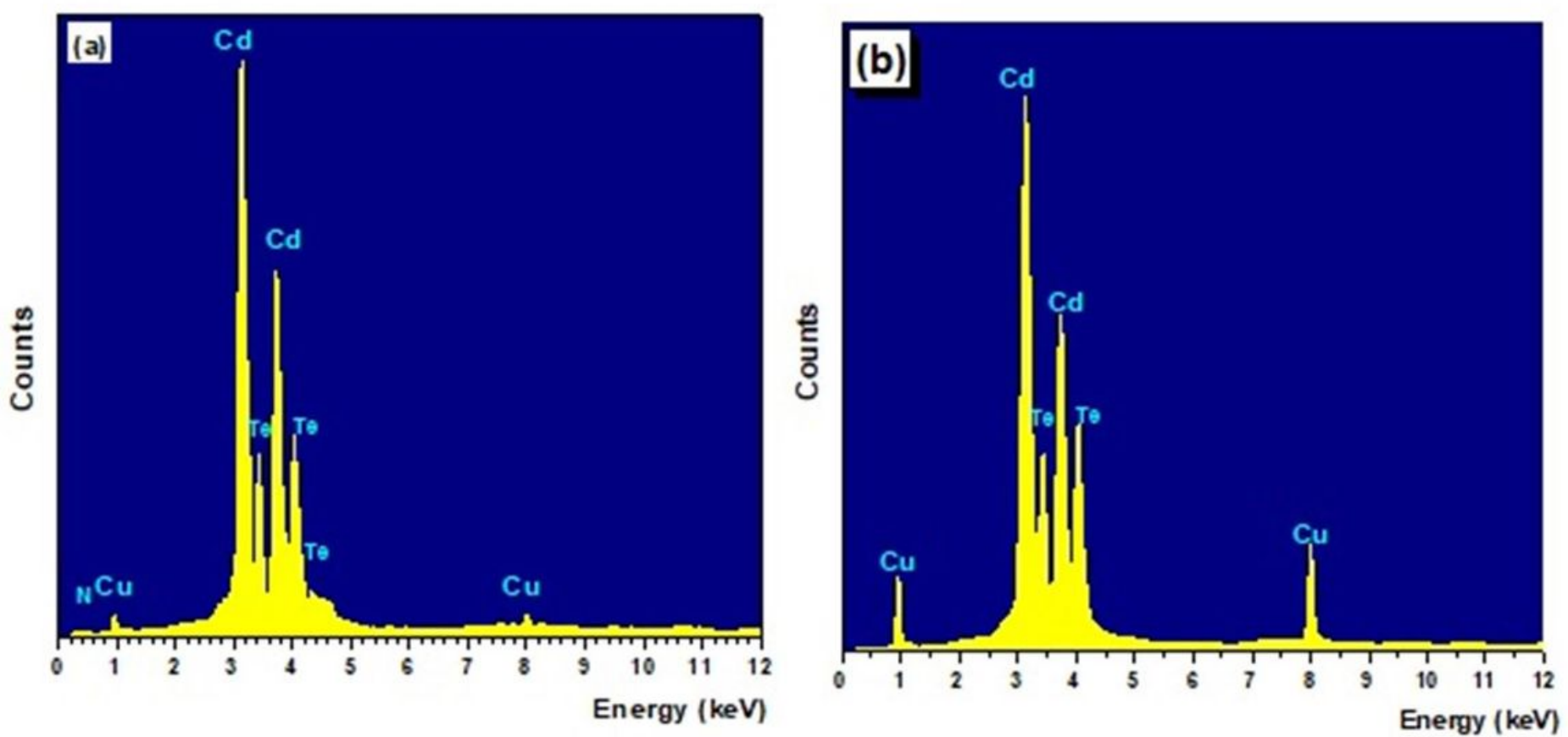

Figure 1

EDXS of the Cu doped CdTe films. 

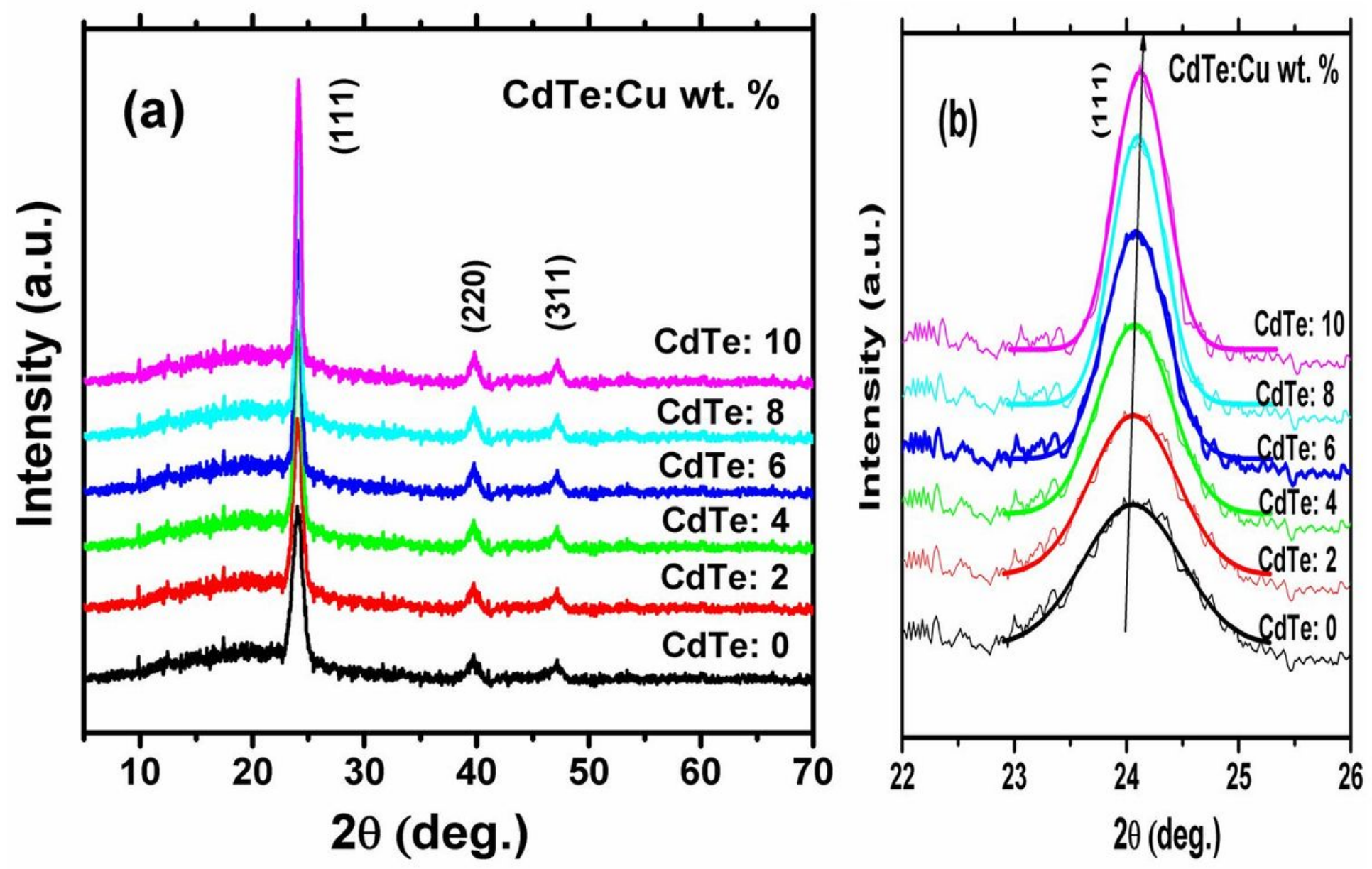

Figure 2

(a) XRD diagrams of undoped and $\mathrm{Cu}$ doped thin films at Cu concentrations, (b) The magnification of diffraction peak at (111) plane. 


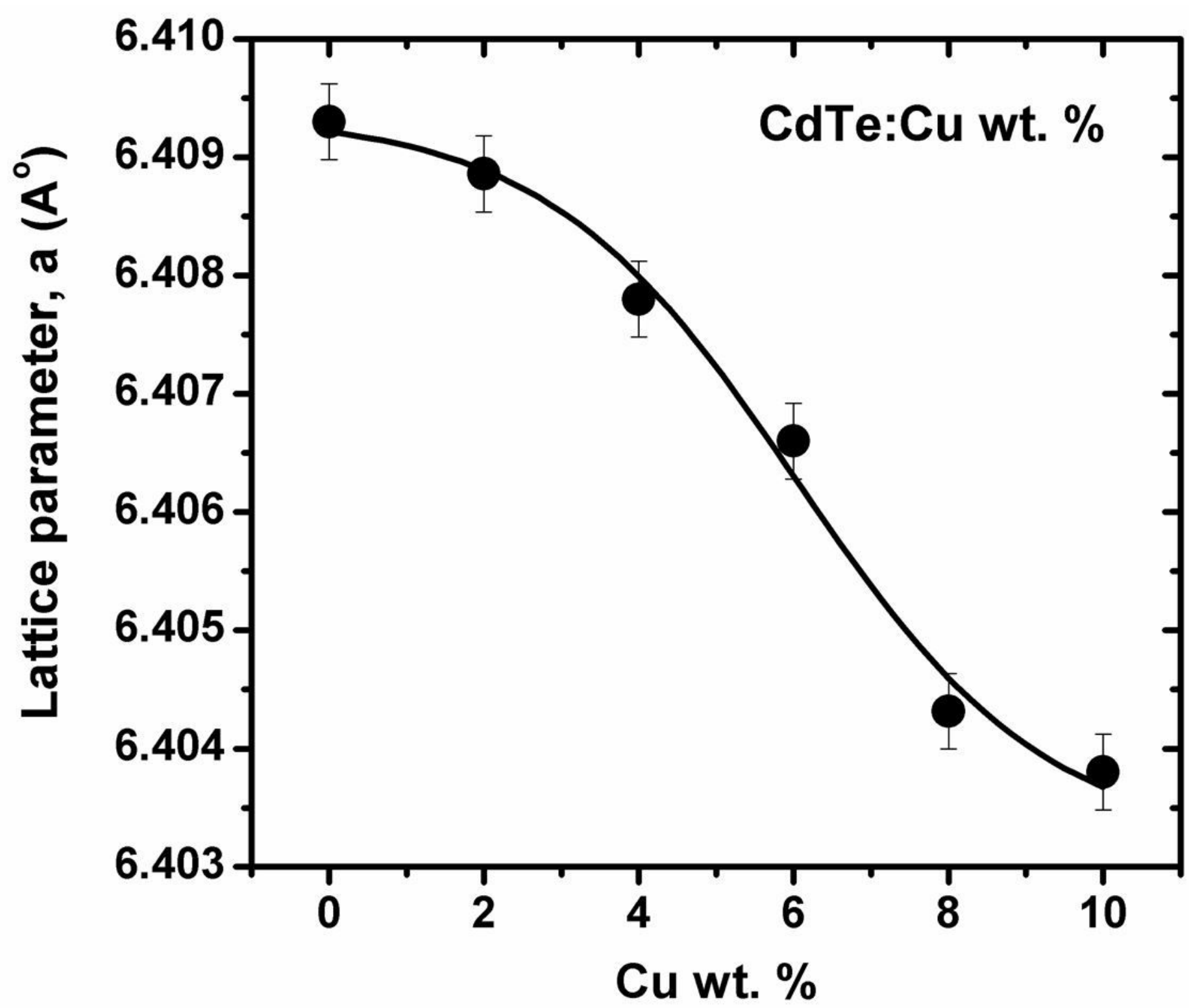

Figure 3

The lattice parameter versus $\mathrm{Cu}$ doping concentration in CdTe matrix. 


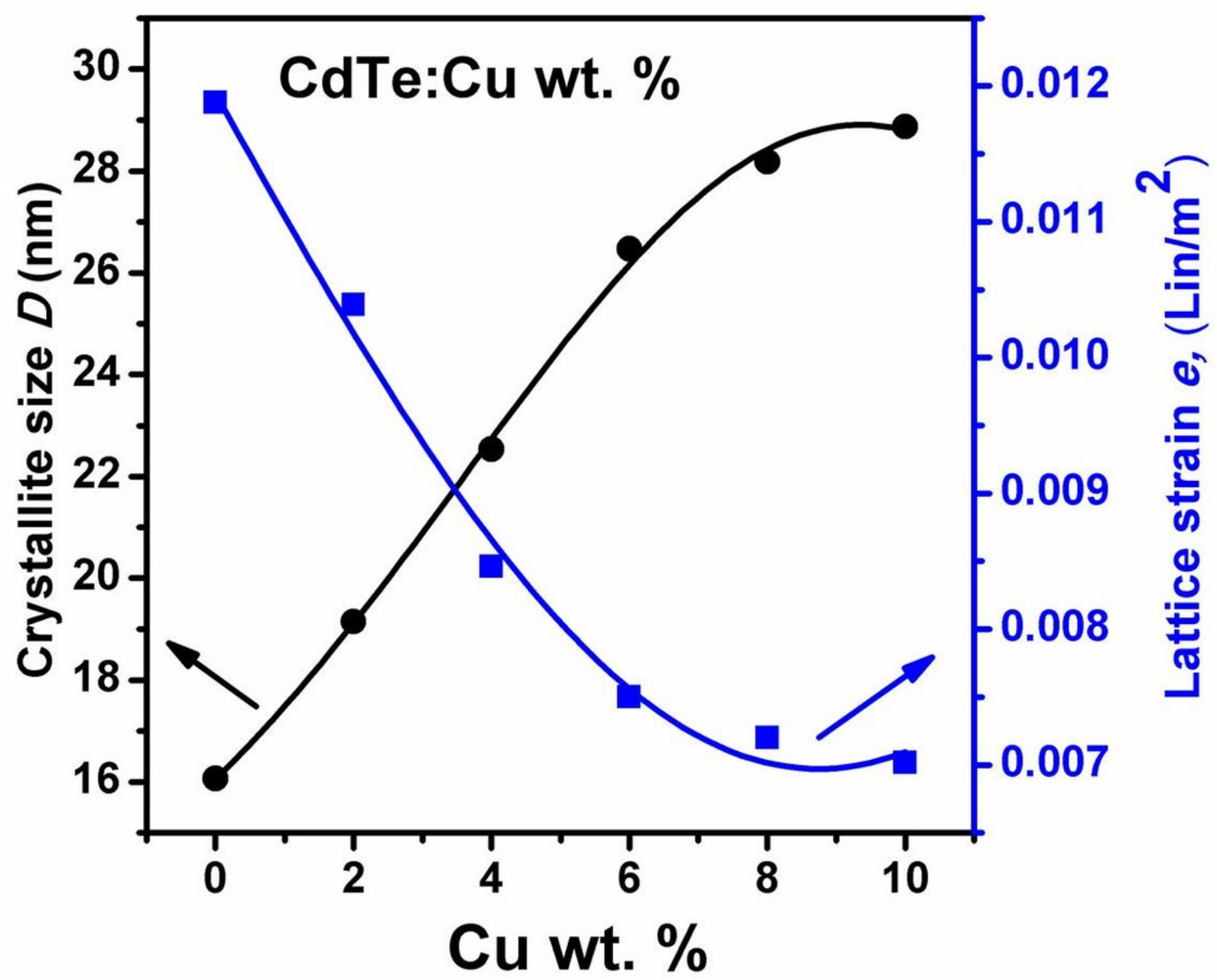

Figure 4

The variation of the microstructural parameters with different $\mathrm{Cu}$ concentrations of undoped and $\mathrm{Cu}$ doped CdTe films. 
(a) CdTe

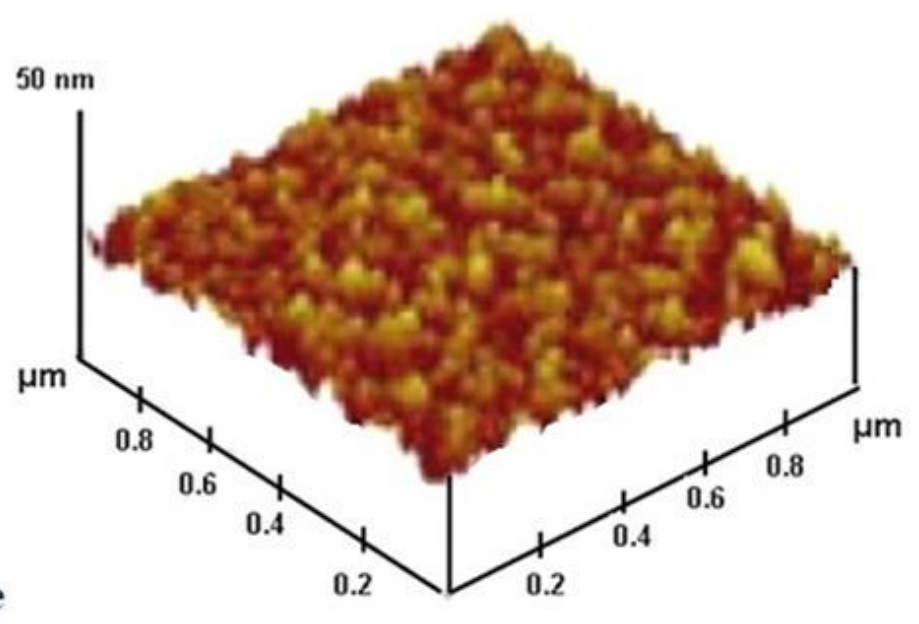

(b) CdTe:4


Figure 5

3D AFM micrographs of Cu doped CdTe films. 




Figure 6

The spectral variation of the transmittance and refractance of pue and $\mathrm{Cu}$ doped $\mathrm{CdTe}$ films with various Cu contents. 




Figure 7

The spectral variation of the transmittance and refractance of pue and $\mathrm{Cu}$ doped $\mathrm{CdTe}$ films with various Cu contents. 


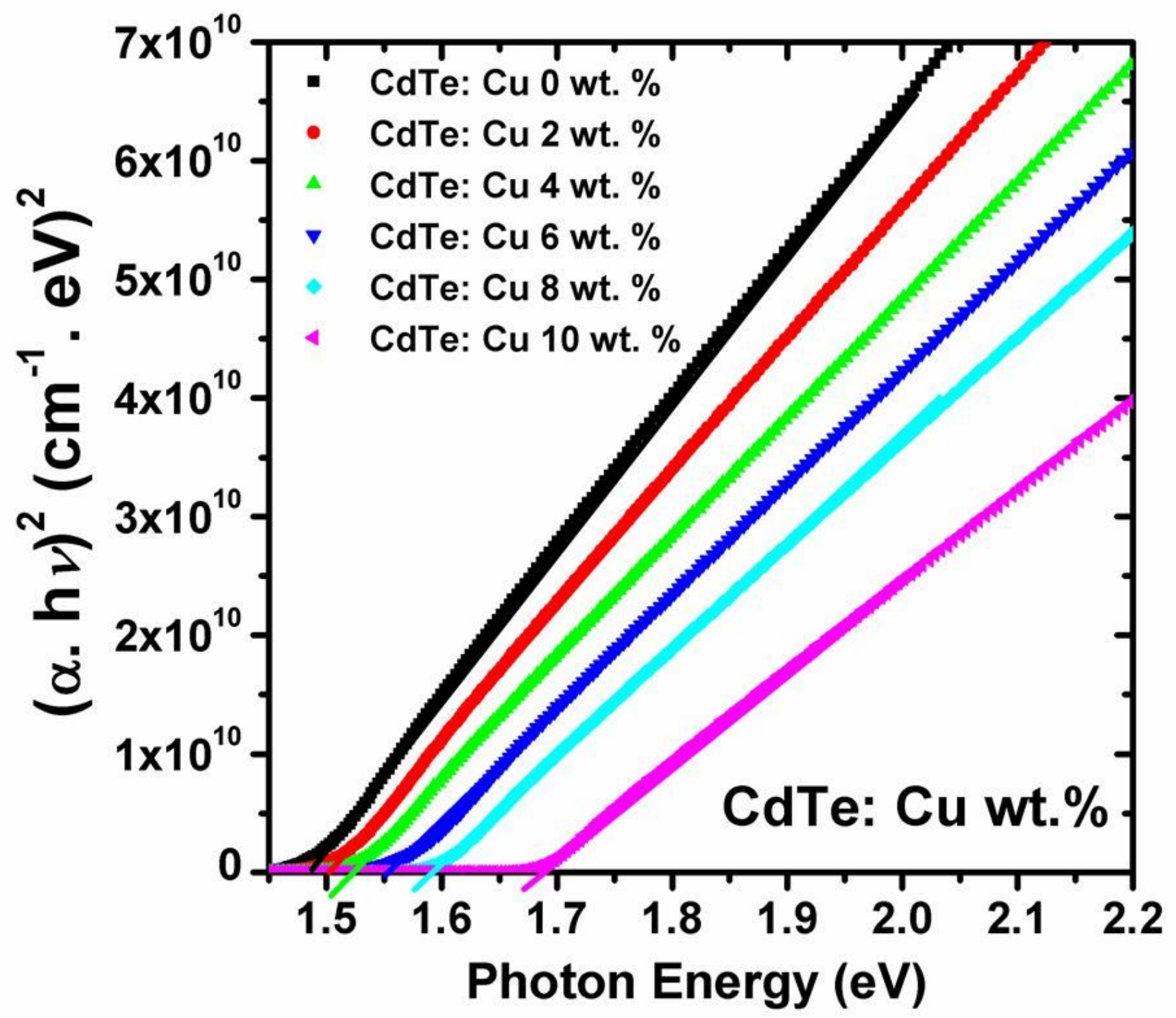

Figure 8

(ahv) 2 versus hv of undoped and Cu doped CdTe films at different Cu contents. 


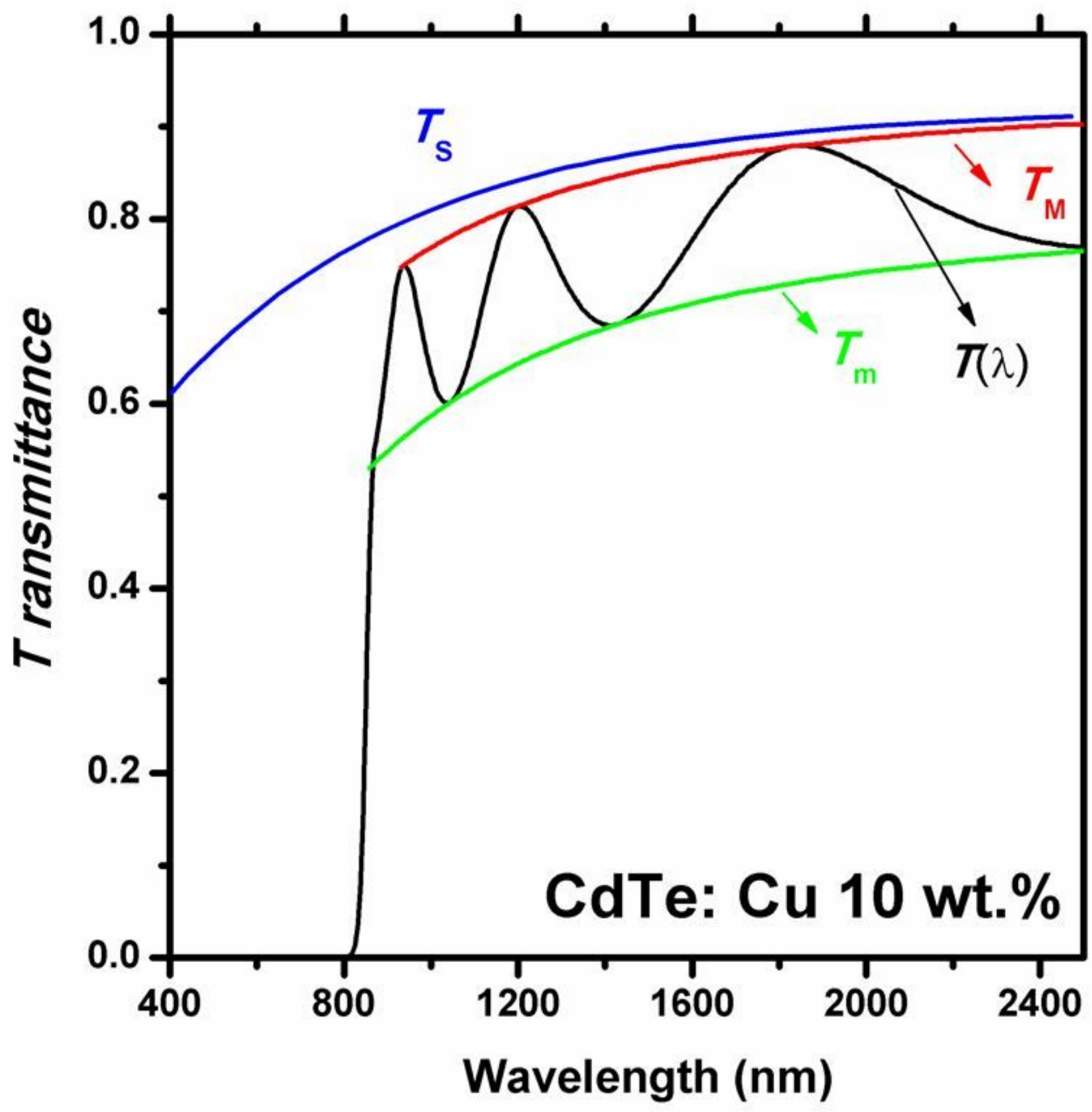

Figure 9

The envelope of the transmittance curve of the CdTe:10 film. 


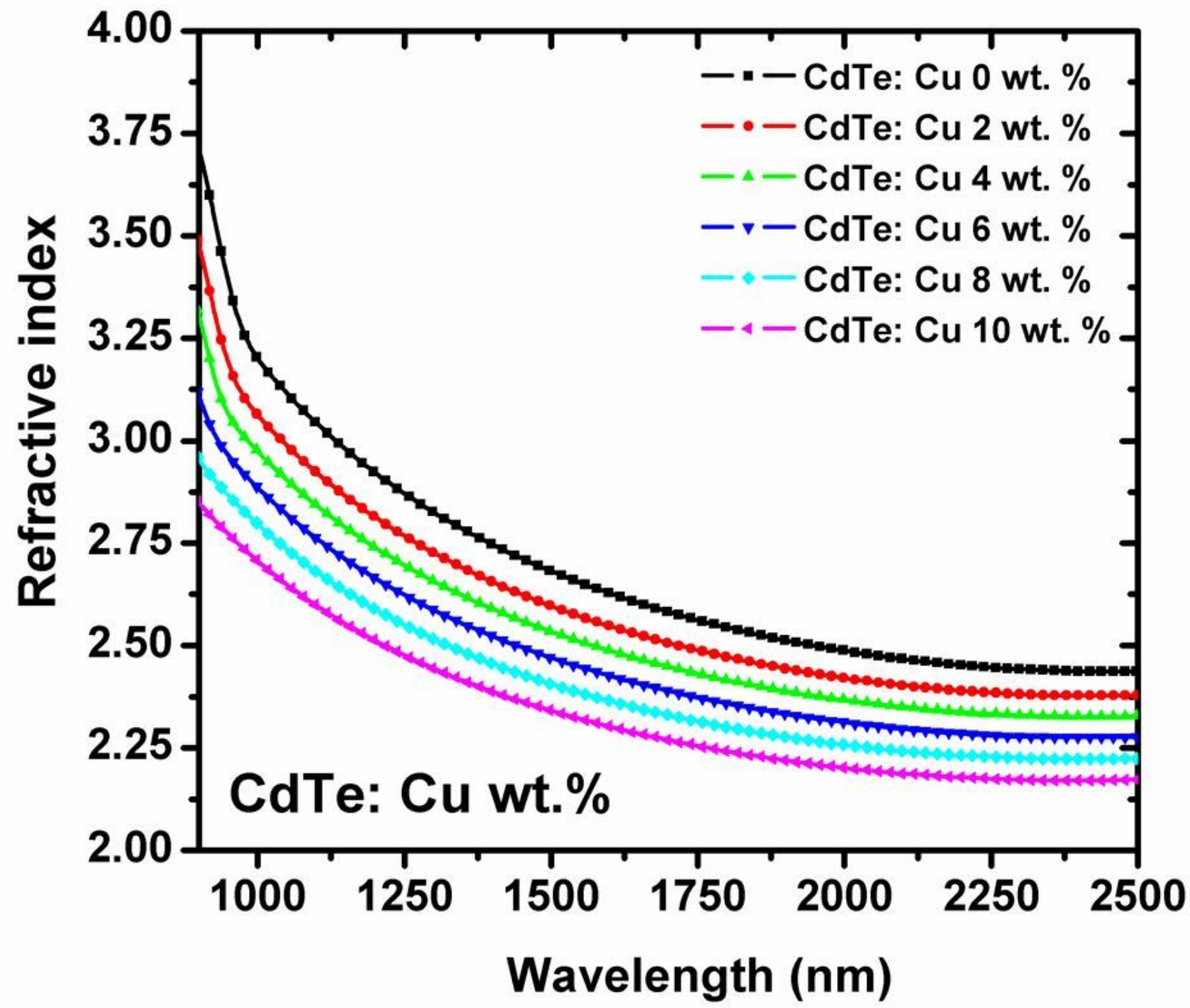

Figure 10

The spectral dependence of the refractive of pure and $\mathrm{Cu}$ doped $\mathrm{CdTe}$ film with different $\mathrm{Cu}$ concentrations. 


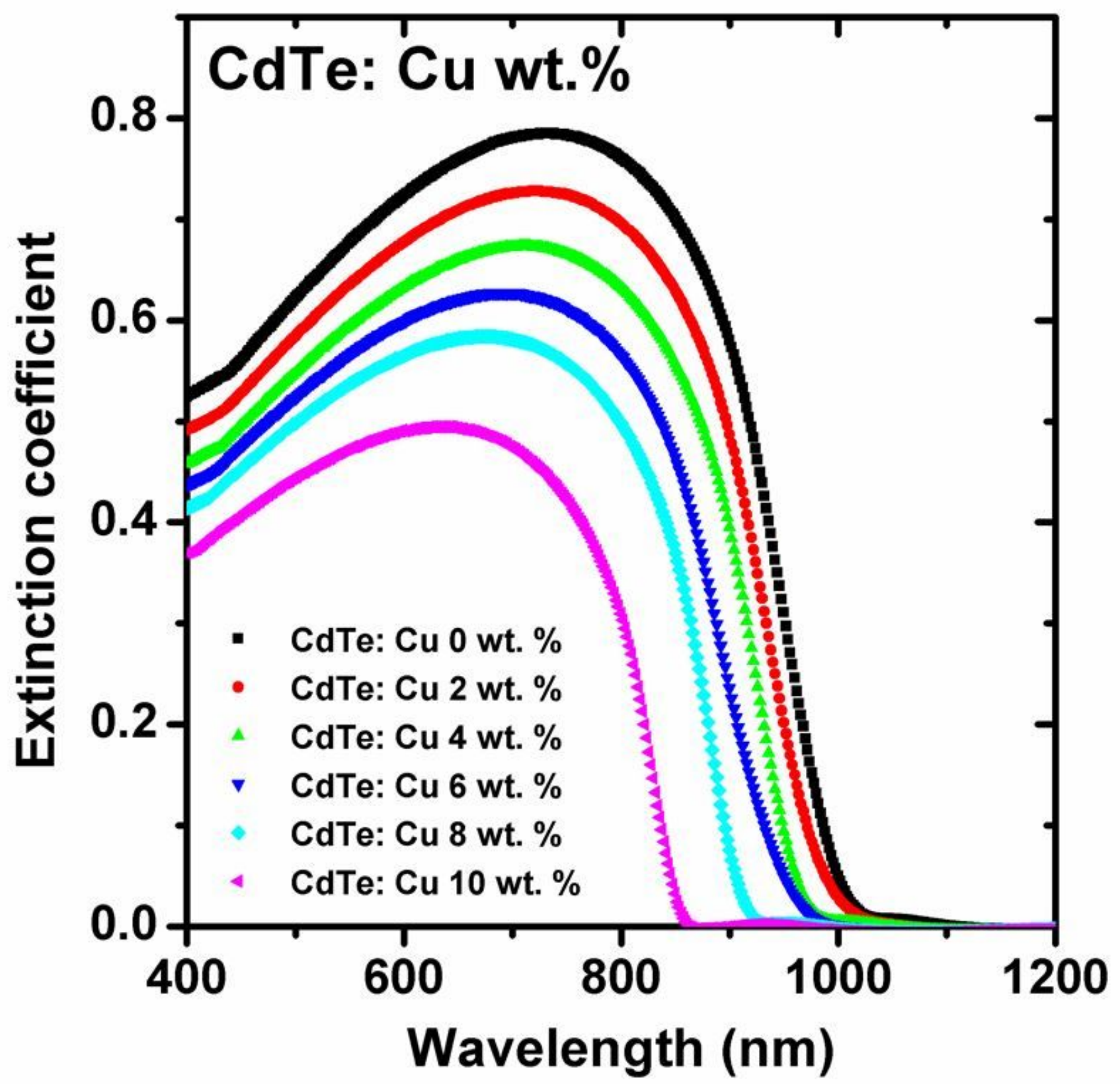

Figure 11

The spectral variation of $\mathrm{k}$ for $\mathrm{Cu}$ doped films with various $\mathrm{Cu}$ doping level. 


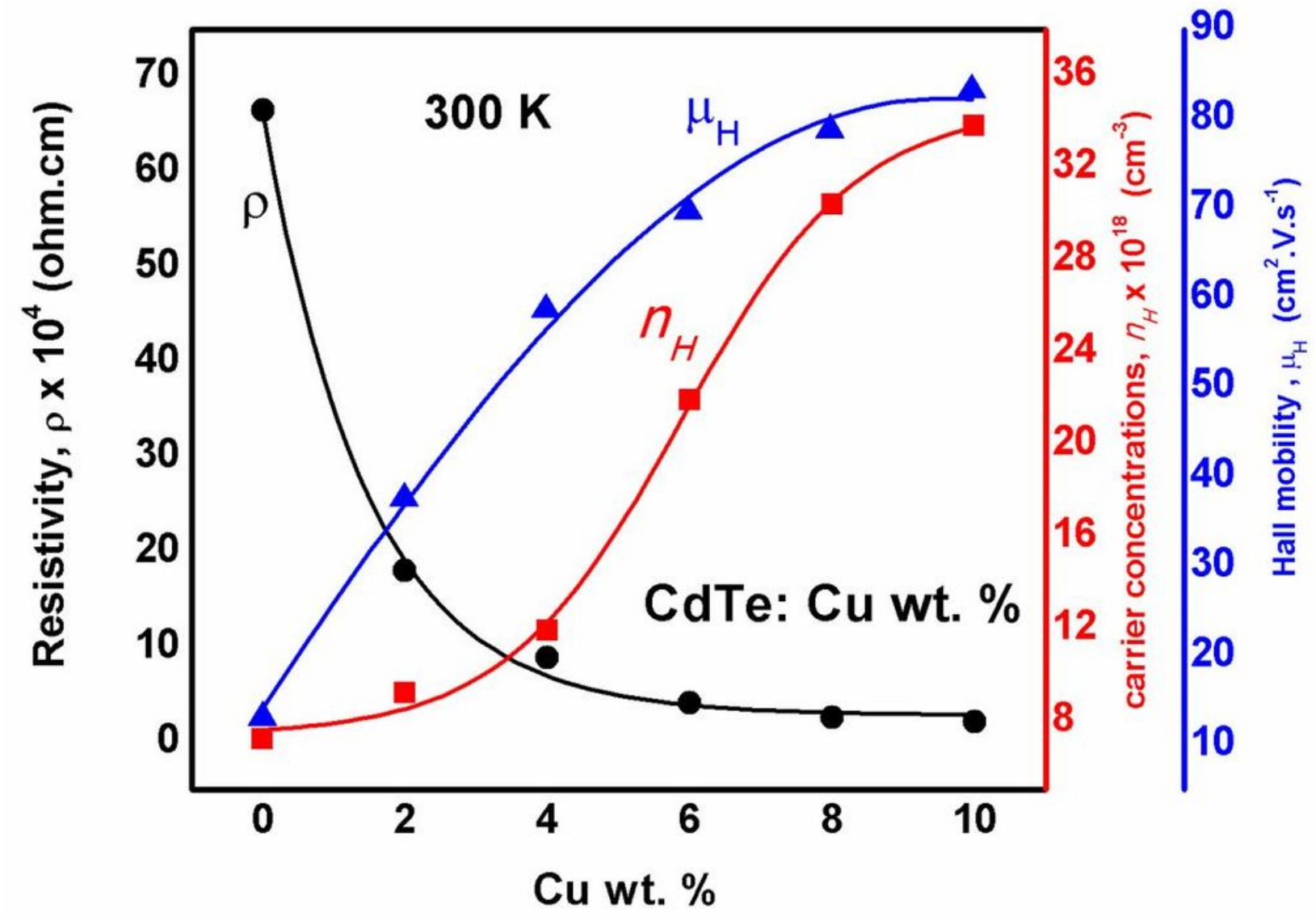

Figure 12

The Hall mobility $\mu \mathrm{H}$, carrier concentrations $\mathrm{nH}$ and resistivity $\rho$ at room temperature of nanostructured undoped and $\mathrm{Cu}$ doped $\mathrm{CdTe}$ film with various Cu doping levels. 




Figure 13

In odc versus 1000/T of undoped and Cu doped CdTe nanostructure film with various Cu doping levels. 


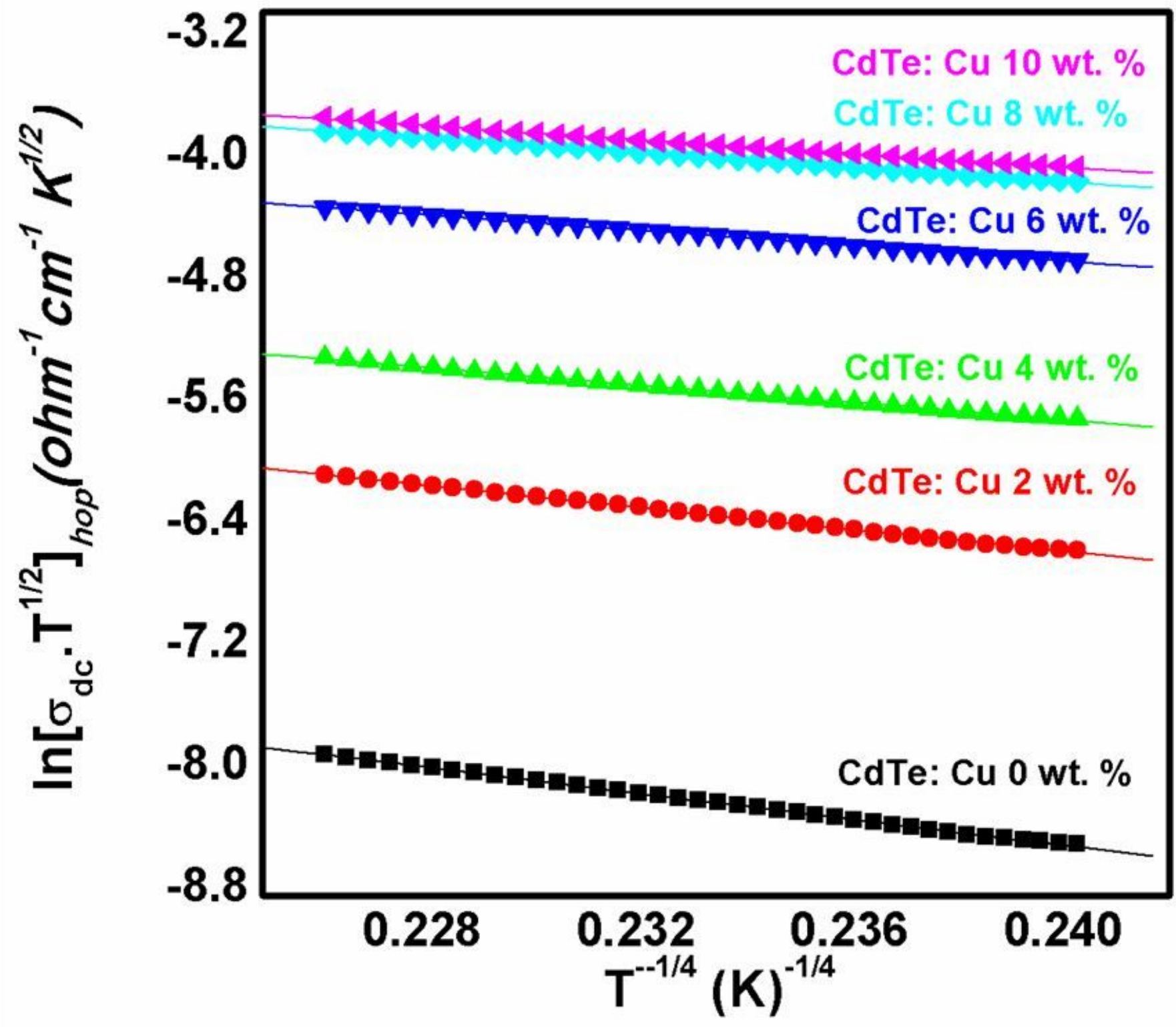

Figure 14

In (odcT1/2) versus T-1/4 of undoped and Cu doped CdTe nanostructure film with various Cu doping levels. 